\title{
Hydrophobically associating polymers for enhanced oil recovery, part a: a review on the effects of some key reservoir conditions.
}

AFOLABI, R.O., OLUYEMI, G.F., OFFICER, S., UGWU, J.O. 


\section{Accepted Manuscript}

Hydrophobically associating polymers for enhanced oil recovery - Part A: A review on the effects of some key reservoir conditions

Richard O. Afolabi, Gbenga F. Oluyemi, Simon Officer, Johnson O. Ugwu

PII: S0920-4105(19)30564-9

DOI: https://doi.org/10.1016/j.petrol.2019.06.016

Reference: PETROL 6152

To appear in: Journal of Petroleum Science and Engineering

Received Date: 28 February 2019

Revised Date: 20 May 2019

Accepted Date: 5 June 2019

Please cite this article as: Afolabi, R.O., Oluyemi, G.F., Officer, S., Ugwu, J.O., Hydrophobically associating polymers for enhanced oil recovery - Part A: A review on the effects of some key reservoir conditions, Journal of Petroleum Science and Engineering (2019), doi: https://doi.org/10.1016/ j.petrol.2019.06.016.

This is a PDF file of an unedited manuscript that has been accepted for publication. As a service to our customers we are providing this early version of the manuscript. The manuscript will undergo copyediting, typesetting, and review of the resulting proof before it is published in its final form. Please note that during the production process errors may be discovered which could affect the content, and all legal disclaimers that apply to the journal pertain. 


\section{Review Article}

Title: Hydrophobically Associating Polymers for Enhanced Oil Recovery - Part A: A Review on the Effects of Some Key Reservoir Conditions.

Authors: Richard O. Afolabi ${ }^{1}{ }^{*}$, Gbenga F. Oluyemi ${ }^{1}$, Simon Officer ${ }^{2}$, Johnson O. Ugwu $^{3}$

Affiliations: ${ }^{1}$ School of Engineering, Robert Gordon University, Aberdeen, AB10 7GJ, United Kingdom.

${ }^{2}$ School of Pharmacy and Life Sciences, Robert Gordon University, Aberdeen, AB10 7GJ, United Kingdom

${ }^{3}$ School of Science, Engineering and Design, Teesside University, Middlesbrough, Tees Valley, TS1 3BX, United Kingdom

*Contact email: r.afolabi@ rgu.ac.uk 


\section{Abstract}

Research advancement in polymer flooding for Enhanced Oil Recovery (EOR) has been growing over the last decade. This growth can be tied to increased funding towards the development of superior polymers such as hydrophobically associating polymers when oil prices were high and increasing concern that "easy oil" has been exploited with the focus now on "difficult to extract" oil. The use of hydrophobically associating polymers for EOR was discussed along with its limitations. In this context, the improved rheological properties of associating polymers cannot only be linked to the molecular structures arising from different synthesis methods. Equally, external parameters similar to conditions of oil reservoirs affect the rheological properties of these polymers. As such, this review placed critical emphasis on the molecular architecture of the polymer and the synthesis route and this was linked to the observed rheological properties. In addition, the influence of some key oilfield parameters such as temperature, salinity, $\mathrm{pH}$, and reservoir heterogeneity on the rheological behaviour of hydrophobically associating polymers were reviewed. In this respect, the various findings garnered in understanding the correlation between polymer rheological properties and oilfield parameters were critically reviewed. For associating polymers, an understanding of the molecular architecture (and hence the synthesis method) is crucial for its successful design. However, this must be theoretically linked to the preferred EOR application requirements (based on oilfield parameters).

Keywords: Enhanced Oil Recovery; Polymer Flooding; Associating Polymers; Associative Polymers; Hydrophobic Interactions; Oilfield Polymers 


\section{Introduction}

Global energy demand in the $21^{\text {st }}$ century is heavily reliant on crude oil despite the decline in discovery of oil reservoirs (Sabhapondit et al., 2003). Research into the use of alternative sources of energy in place of that generated from crude oil is proven but yet to be fully developed to meet the world's burgeoning energy needs. Hence, the present energy demand is met by a mix of traditional energy sources (from crude oil) and alternative energy sources (such as wind or solar) (Wever et al., 2011). "Easy to Extract Oil" which mainly represents oil recovered by conventional primary and secondary means is generally running out. It is estimated that $7.0 \times 10^{12}$ barrels of "Difficult to Extract Oil" will remain in matured fields after conventional methods have been utilized (Wever et al., 2011; Wever et al., 2013; Li et al., 2017). This amount of oil remaining represents the focus of various tertiary recovery schemes for which Enhanced Oil Recovery (EOR) constitutes the umbrella (Silva et al., 2018; Sharafi et al., 2018). With over a trillion barrels of oil estimated to remain globally, multinational oil companies have increased their research and development investment over the last decade. When oil prices were high, the EOR researches conducted by oil companies were armed with huge budgets. This resulted in significant advances through the developments of new chemicals in the form of hydrophobically associating polymers, surfactants, and gels (Taylor and Nasr El-Din, 1998; Levitt and Pope, 2008; Wever et al., 2013; Al-Sabagh et al., 2016; Raffa et al., 2016). China remains the largest employer of polymer flooding for EOR (Zhong et al., 2017). The Shengli and Daqing fields in China were effectively produced using polymer flooding (Bai et al., 2018). It was estimated in 2015 that the cumulative oil reserve produced using polymer flooding in China was one billion tons ( $1 \times 10^{9}$ tons) which is about $13 \%$ of the Original Oil in Place (OOIP) (Liao et al., 2017; Bai et al., 2018). Furthermore, polymer-flooding technology was applied in heavy oil recovery in the Pelican Lake field in Alberta, Canada with oil viscosity in the range of $1000-2500 \mathrm{cp}$. 
This represents a major breakthrough in heavy oil production where thermal recovery mechanisms have failed (Delamaide et al., 2013; Li et al., 2018). Recently, Chevron commenced polymer flooding at the Captain Field in the North Sea. The offshore location of the field required that the polymer was procured in liquid emulsion (Beckham, 2018). The key objective of using polymers is to increase the viscosity of the aqueous phase after secondary recovery scheme in matured oil reservoirs (Abidin et al., 2012; Kamal et al., 2015; Silva et al., 2018). This is achieved through improved microscopic sweep and displacement efficiency (Sun et al., 2015; Akbulut and Temizel, 2017; El-Hoshoudy et al., 2017; Li et al., 2018). Polymers are classified as viscoelastic in nature with shear thinning and thickening behaviour in porous media (Yin et al., 2006; Zhang et al., 2008; Gong and Zhang, 2009; Skauge, et al., 2018). A water-soluble polymer should characteristically withstand the inherent conditions associated with an oil reservoir. This is particularly important as oil reservoirs are mostly under high salinity, temperature and divalent ion concentration (Oruwori and Ikiensikimama, 2010; Wever et al., 2011; Lai et al., 2013; Choi et al., 2014; AlSabagh et al., 2016; Raffa et al., 2016; Das et al., 2017; Sarsenbekuly et al., 2017; Bai et al., 2018; Silva et al., 2018). Furthermore, the search for new oil reserves has pushed the bounds of the industry into deep offshore locations which are under extreme reservoir conditions. Moreover, polymers employed should also be able to withstand lengthy injection time and shear. Beyond the identified oilfield parameters, offshore application of polymer flooding requires it to satisfy the requirements of offshore platforms (Zhou et al., 2008; Gao, 2011; Kang et al., 2016). The lifespan of offshore platforms is limited and this requires oilfield operators to identify an effective and efficient EOR scheme to extract oil (Zhou et al., 2008). Therefore, application of polymer flooding is often conducted early in the development of an oil reservoir (Wei et al., 2007; Zhou et al., 2008; Delamaide et al., 2013). 
The field of polymer flooding still remains thought provoking due to the broad variety of polymers which have been developed and studied at academic and industrial level for over two decades (Wever et al., 2011). Undeniably, hydrophobically associating polymers remains a fundamental paradigmatic polymer product developed over this period of time. Scientific studies which have linked hydrophobically associating polymers to chemical flooding have focused on its sustained thickening ability under conditions including temperature, salinity and ion concentration. This was explained by the intermolecular association between the polymer chains at a concentration above the critical aggregation concentration (CAC) (Figure 1). The CAC of hydrophobically associating polymers can be described as the threshold concentration that characterizes the behavior of the polymers. Below the CAC, intramolecular interaction within the polymer chain dominates the rheology (Taylor and Nasr El-Din, 1998; Yabin et al., 2001; Feng et al., 2005; Lu et al., 2010; Afolabi, 2015). This theoretical understanding has paved the way for the potential application of hydrophobically associating polymers for EOR operations. However, this common understanding has been a subject of intellectual probing and discussion in the last decade. This is evident from the numerous scientific publications on the subject of associating polymers over this period. The last dedicated review article on hydrophobically associating polymers for enhanced oil recovery by Taylor and Nasr El-Din (1998) has been made obsolete by new discoveries emanating especially from field trials. In 2005, hydrophobically associating polymers were successfully tested for an EOR scheme in Bohai Bay, China. The incremental oil recovery was recorded to be $25,000 \mathrm{~m}^{3}$ with water cut decreasing from 95 to $54 \%$ (Wei et al., 2007; Kamal et al., 2015). More recently, production from the Perm field in Russia was implemented using hydrophobically associating polyacrylamide in 2013 (Patokina, 2015). In 2018, a binary system consisting of an associative polymer and surfactant was evaluated for a flooding pilot scheme in Guan-109 faulted blocked reservoir in Dagang, China (Guo et al., 
2018). The valuable findings from these field trials can form the basis of future research targeted toward the full implementation of hydrophobically associating polymers. For example, recent studies on the adsorption phenomenon associated with hydrophobically modified polymers have been attributed to some "minor polymeric species" (Dupuis et al., 2011; Seright et al., 2011). As such, new knowledge is required on the origin of these species and how they can be effectively filtered from the bulk polymer. Consequently, this review focuses on the following:

a) Developmental strides gained through the synthesis of new polymers such as hydrophobically associating polymers and comparison of its solution properties with conventional polymers;

b) Explanation of the correlation between the solution properties and the polymer molecular structure;

c) The impact of oilfield parameters such as salinity, temperature, ion concentration, shear and reservoir heterogeneity on thickening properties of hydrophobically associating polymers.

\section{Hydrophobically Associating Polymers}

Conventional polymers such as polyacrylamide (PAM), hydrolyzed polyacrylamide (HPAM) and Xanthan Gum employed for EOR operations have a number of challenges associated with them. PAM/HPAM polymers are susceptible to loss of viscosity under extreme reservoir conditions. On the other hand, while Xanthan Gum may withstand high salinity conditions, its biodegradability has hampered its sustained use for EOR operations. These strengths and weaknesses are reflected in their field applications as shown in Table 1. From Table 1, Xanthan Gum and hydroxyethyl cellulose (HEC) show good field applicability under high salinity conditions compared to HPAM/PAM. Above all, the need to mitigate the challenges associated with the use of PAM/HPAM and biodegradable polymers for EOR purpose has 
necessitated increased research into chemical derivatives of polyacrylamide (Taylor and Nasr El-Din, 1998; Guo et al., 2012; Ye et al., 2013; Chen, 2016; Dai et al., 2017). An important derivative is a hydrophobically associating polyacrylamide (HAPAM). The underlying goal for these derivatives was to improve the thickening capability of polyacrylamides under harsh reservoir conditions such as high temperature high salinity (HTHS) (Wever et al., 2013; Chen, 2016; Dai et al., 2017). The improved thickening capability of associative polymers ensures that it has a higher mobility reduction compared to HPAM polymers. This high mobility reduction by associative polymers translates to higher incremental oil recovery compared to HPAM polymers. Recently, it has been shown that for viscoelastic polymers, there is a transition from steady laminar flow to a strongly fluctuating flow consistent with elastic turbulence (Clarke et al., 2015; Cui et al., 2016). The onset of this elastic turbulence (or flow fluctuations) has been identified as the mechanism behind the additional mobilization of trapped oil (capillary desaturation through destabilization of trapped oil). At flow rate greater than the onset for shear thickening, extensional viscosity cannot be taken as the reason for additional oil recovery when the capillary number $(\mathrm{Ca})$ is less than the threshold $(\mathrm{Ca} \leq 1)$. Thus, the degree of trapped oil mobilization is a function of the extent of elastic turbulence generated. Therefore, the incremental recovery of associating polymers could be due to the additional effect of intermolecular association (hydrophobic interaction) on elastic turbulence for flow in porous media. Laboratory studies on HAPAM as shown in Table 2 are numerous however, comparison with Table 1 indicate limited field application. More importantly, this comparison indicate that with the level of scientific research on HAPAM, it would eventually replace HPAM for polymer flooding operations. These associative polymers are synthesized or produced with the incorporation of hydrophobic comonomers along the polymer backbone. Accordingly, these hydrophobic monomers contribute to the overall molecular weight of the polymers. In addition, HAPAM polymers 
are characterized by a CAC (see Figure 1). The enhanced rheological properties of HAPAM is obvious above the CAC, which can be traced to the intermolecular association between polymer chains (Zhu et al., 2014; Cui et al., 2016; Wever et al., 2011). However, these interactions between polymer chains above the $\mathrm{CAC}$ is dependent on the distribution of the hydrophobic comonomers along the polymer chain. These distributions can be random or block-like and it is determined by the conditions of the synthesis procedure (Wever et al., 2011). As mentioned earlier, the method of synthesizing HAPAM polymers significantly influences the hydrophobe distribution on the polymer chain. The chemical synthesis of polyacrylamide is via a free radical polymerization (Giz et al., 2001; Qavi et al. 2014; Rintoul, 2017; Yamamoto et al., 2017; Shatat and Niazi, 2018). Notwithstanding, the insoluble nature of the hydrophobic comonomer has led to the chemical modification of the synthesis route for HAPAM polymers (Zhang et al., 2017). Hence, the different methods available for synthesizing HAPAM polymers include homogeneous, heterogeneous and micellar copolymerization (Taylor and Nasr El-Din, 1998; Wever et al., 2011). Each method ensures the solubility of the hydrophobe with either a surfactant or co-solvent as in the case of micellar and homogenous copolymerization respectively. However, the heterogeneous copolymerization method does not use any additive in ensuring the dispersion of the hydrophobic comonomer. The most widely used polymerization technique for HAPAM is the micellar copolymerization method in comparison with the other techniques (Candau et al., 1994; Candau and Selb, 1999; Taylor and Nasr El-Din, 1998; Wever et al., 2011; Chen, 2016). Significantly, the key advantage of this method is that the produced polymer ends up with a block-like distribution of the hydrophobic comonomer on the polymer chain. However, this is particularly dependent on the molar ratio of the surfactant employed to the hydrophobic comonomer (Candau et al., 1994; Taylor and Nasr El-Din, 1998; Candau and Selb, 1999; Wever et al., 2011; Kamal et al., 2015). A molar ratio involving a single 
hydrophobic unit contained in a single micelle would increase the randomness of the distribution of hydrophobe on the polymer chain. On the other hand, where the number of hydrophobe units contained in a particular micelle is greater than one, a block-like distribution of the hydrophobe would be obtained. Alternatively, while micellar copolymerization uses a surfactant in solubilizing the hydrophobe, another modification to the process involves the use of a polymerizable surfactant (Wever et al., 2011). The use of a polymerizable surfactant ensures that the purification process of the final polymer product for removal of surfactants may not be required. Nevertheless, the challenge with this approach lies in the identification of the desired polymerizable surfactant (Wever et al., 2011). Other parameters which affect the synthesis of HAPAM polymers via micellar copolymerization include type of initiator, temperature, type and content of surfactant and the molar ratio of monomers (Candau et al., 1994; Taylor and Nasr El-Din, 1998; Wever et al., 2011; Kamal et al., 2015). Another synthesis approach to HAPAM polymers involves the technique of template copolymerization (Yan and Row, 2006; Hood et al., 2014; Feng et al., 2017; Szymański et al., 2018). A template predefines the molecular configuration of the associating polymer, which ensures that the block-like distribution of the hydrophobe constituents is well ordered. The consequence of this is that the block of hydrophobe content on the polymer chain can be extensive. The thickening capability of water-soluble polymers relates to its hydrodynamic volume in aqueous solution (Deen 2012; Chen, 2016; Feng et al., 2017). For PAM/HPAM polymers, this is dependent on electrostatic repulsion between charged carboxylate groups along the chain (Abidin et al., 2012; Choi et al., 2015; Gong et al., 2017). In the case of HAPAM, this can be achieved using zwitterion monomers, which have negative and positive charges. The thickening ability is controlled by external parameters on the polymers such as ionic strength and $\mathrm{pH}$ (Nesrinne and Djamel, 2017). However, polymers for EOR applications would require that the thickening ability of the polymers is independent 
of/or can tolerate these conditions. Therefore, having HAPAM polymers with charge distribution along the polymer chain would ensure control over the rheology in aqueous solution (Wever et al., 2011). In addition, the associative behavior of HAPAM polymers can be increased by the amount of hydrophobe (hydrophobicity) present in the polymer chain. Whereas, when the hydrophobe length on the polymer chain becomes too long, the solubility of the polymer is affected and this may result in polymer dissolution challenges for field application. Consequently, there is a need for an optimum hydrophobe content when synthesizing HAPAM polymers. The determination of this optimum concentration of hydrophobic comonomer required has not been a subject of extensive research. However, the synthesis of associating polymers for EOR application would require the knowledge of the predefined conditions of oil reservoirs. This is important as an excess amount of hydrophobe content may have far-reaching implications when the solubility of HAPAM polymers is considered. In like manner, the thickening properties of HAPAM polymers can be influenced by the introduction of water-soluble chemical spacers in the molecular configuration (Li-Bin et al., 2010; Wever et al., 2011). The chemical spacers are there to link the hydrophilic backbone of the polymer to the hydrophobic group. Li-Bin et al. (2010) investigated the effect of ethylene oxide spacer length on the solution properties of water-soluble hydrophobically associating poly (acrylic acid-co-Rf-PEG Macromonomer) containing fluorocarbon. From the rheological study carried out, the authors discovered that the hydrophobic association increased with ethylene-oxide spacer length. This, in turn, influences the thickening performance of the polymer with a similar result on the effect of spacer length reported by Noda et al. (2001). Characterization of the hydrophobic interactions have been investigated extensively using pyrene, which is a probe employed for fluorescence spectroscopy (Prazeres et al., 2001; Tang et al., 2003; Pandey et al. 2003; Bains et al., 2011; Mei et al., 2016). The low solubility of pyrene in water and its unique emission spectrum 
makes it the preferred choice in the study of hydrophobic interactions in molecules (Siu and Duhamel, 2008; Jordan and Gibb, 2015). The fluorescence spectroscopy studies on hydrophobically associating polymers using pyrene have shown that there are three distinct flow regimes characterizing such polymers (Gong and Zhang, 2009; Duhamel, 2012). At polymer concentration below the $\mathrm{CAC}$, the associative interactions are more intramolecular in nature. It has been discovered that the onset of hydrophobic association between polymer chains occurs at concentration values closer to the CAC (Taylor and Nasr El-Din, 1998). Using fluorescence spectroscopy, this is manifested in a shift in the emission spectrum associated with the solubilization of pyrene by hydrophobic clusters. Between this onset concentration value and the $\mathrm{CAC}$, there exists some form of hydrophobic interactive influence but its dominant effect is minimal. Although CAC is regarded as the start of associative characteristics in hydrophobically associating polymers, the proper characterization of the onset concentration value mentioned earlier may change this knowledge. Furthermore, the minimal hydrophobic clusters may not solubilize pyrene enough for a unique emission spectrum to be detected. This onset concentration value differs from the CAC based on the extent of hydrophobic association and may be classified as a transition period. At polymer concentrations above the CAC, there tends to be an extensive network of intermolecular association between polymer chains, which leads to an increase in the polymer viscosity. This is captured in fluorescence spectroscopy by a characteristic emission spectrum, which is not the case at the onset concentration value. Table 3 presents some of the comonomers usually employed in modifying the rheology of both acrylamide-based polymers and other types of polymers made from the different monomeric units. Additionally, these comonomers ensure that the modified polymer is resistant to conditions, which may initiate chemical and mechanical degradation. Moreover, these comonomers ensure that the modified polymer maintains a substantial part of its hydrodynamic volume, hence its viscosity, under 
the conditions obtainable in an oil reservoir (Kamal et al., 2015; Das et al., 2017; Sarsenbekuly et al., 2017; Bai et al., 2018; Silva et al., 2018). Characterization of the molecular architecture of HAPAM polymers have been conducted using infrared (IR) spectroscopy and nuclear magnetic resonance (NMR) spectra (Lai et al., 2013). This allow determination of the chemical bonding arising from the presence of certain functional groups. The use of FTIR alone cannot give a complete description of the molecular structure of a polymer, hence it is used along with NMR for a complete characterization of the molecular configuration. This was the case when Quan et al. (2019) characterized a hydrophobically associating polymers which was abbreviated as HPAAT. The polymer was synthesized from acrylamide (AM), allyl polyethylene-1000 (APEG), octadecyl dimethyl allyl ammonium chloride (DMDAAC-18) and sodium styrene sulfonate (SSS) using FTIR and ${ }^{1} \mathrm{H}-\mathrm{NMR}$ spectroscopy. Figure 2 shows the FTIR spectrum of the synthesized polymer with the absorption bands at $1715 \mathrm{~cm}^{-1}$ and $3448 \mathrm{~cm}^{-1}$ corresponding to $\mathrm{C}=\mathrm{O}$ and $\mathrm{N}-\mathrm{H}$ stretching vibrations of the amide groups. The peaks at $778 \mathrm{~cm}^{-1}$ and $1414 \mathrm{~cm}^{-1}$ corresponds to benzene ring and $\mathrm{S}=\mathrm{O}$ which confirms the presence of SSS. Furthermore, the peak at $1128 \mathrm{~cm}-1$ shows $\mathrm{C}-\mathrm{O}-\mathrm{C}$ stretching vibrations which confirms the existence of APEG in the associative polymer HPAAT. The peaks at $2920 \mathrm{~cm}^{-1}$ and $2855 \mathrm{~cm}^{-1}$ indicates the existence of hydrocarbon groups $-\mathrm{CH}_{3}$ and $-\mathrm{CH}_{2}$ - in the polymer. The result of the characterization study using FTIR was consistent with molecular design structure of the polymer as shown in Figure 3. Equally important is the ${ }^{1} \mathrm{H}-\mathrm{NMR}$ analysis of the HPAAT polymer carried out by the authors. The analysis indicate a shift of the hydrogen spectrum of the associative polymer in the following manner: $1.09(\mathrm{~m},-\mathrm{CH} 3), 1.25-1.36(\mathrm{c},-(\mathrm{CH} 2) 15-), 1.62\left(\mathrm{r}, 1, \mathrm{~g},-\mathrm{CH}_{2}-\mathrm{CH}-\mathrm{C}-\right.$ $\left.\mathrm{O}-\mathrm{NH}_{2},-\mathrm{CH}_{2}-\mathrm{CH}-\mathrm{CH}_{2}-,-\mathrm{CH}_{2}-\mathrm{CH}-\mathrm{C}\right), 1.71$ (q, $\left.-\mathrm{N}-\mathrm{CH}_{2}-\mathrm{CH}_{2}-\right), 2.14$ (n, b, $-\mathrm{CH}-\mathrm{CH}_{2}-\mathrm{O}-$ , $\left.-\mathrm{CH}-\mathrm{CH}_{2}-\mathrm{N}\right), 2.26(\mathrm{~s},-\mathrm{CH}-\mathrm{C}-\mathrm{O}-\mathrm{NH} 2), 3.22\left(\mathrm{z}, \mathrm{x},-\mathrm{n}-\mathrm{CH}_{2}-, \mathrm{CH}_{2}-\mathrm{N}-\right), 3.30\left(\mathrm{j},-\mathrm{N}-\mathrm{CH}_{3}\right)$, $3.63\left(\mathrm{k},-\mathrm{CH}_{2}-\mathrm{O}-,-\mathrm{CH}_{2}-\mathrm{CH}_{2}-\mathrm{O}-\right), 7.21\left(\mathrm{t},-\mathrm{NH}_{2}\right), 7.67(\mathrm{~h},-\mathrm{CH}-\mathrm{CH}-\mathrm{C})$. Similarly, El- 
Hoshoudy et al. (2015) used FTIR, ${ }^{13} \mathrm{C}-\mathrm{NMR},{ }^{1} \mathrm{H}-\mathrm{NMR}$, scanning electron microscope (SEM), thermogravimetric analysis (TGA) and high resolution transmission electron microscope (HRTEM) to characterize a HAPAM polymer (Acrylamide-4-Dodecylbenzenesulfonate-1-vinylimidazol-3-ium-Divinyl sulfone). Using a similar approach to Quan et al. (2019), the authors used the FTIR and ${ }^{1}$ H-NMR spectra to propose a chemical structure for the associative polymer. Similarly, the SEM image of the studied HAPAM polymer indicated a 3-dimensional structure arising from intra and intermolecular association between polymer chains. The authors concluded that the mesoporous structure of the polymer surface from the SEM analysis can be attributed to the crystallinity of the polymer due to the polar amide group which ensures a secondary attractive force arises from hydrogen bonding. This was also the case for studies carried out on types other polyacrylamide based hydrophobically associating polymers (El-Hoshoudy et al., 2017). However, Sheng (2011) reported that the 3dimensional structural network formed by hydrophobically associative polymers occurs due to a combination of strong electrostatic force, hydrogen bonding and van der Waals forces. Other forms of associating polymers based on ethoxylated urethane (EUR), hydroxyethylcellulose (HEC) derivatives and alkali swellable emulsion (ASE) have been described in literature (Tam et al. 1998; Xu et al. 1996; Kastner et al. 1996; Ihara et al. 2004; Kawakami et al. 2006; Zhao and Chen, 2007; Kjoniksen et al. 2008; Wever et al. 2011). Some of these polymers were produced because of the demand for eco-friendly materials. Associating polymers based on EUR are classified as telechelic associative polymers with enhanced rheological features even at low concentration and molecular weight. Moreover, these unique characteristics have made hydrophobically modified EUR polymers the focus of research for various commercial applications (Wever et al. 2011; Wang et al. 2016). The synthesis of hydrophobically modified EUR polymers results in a hydrophilic polyethylene glycol (PEG) main chain with hydrophobic groups attached to the polymer chain through the 
urethane functional group (Barmar et al. 2010; Wang et al. 2016). Additionally, the associative behavior in these polymers occurs at low concentration values of CAC. Above the $\mathrm{CAC}$, the molecular arrangement of these polymers in aqueous solution ranges from flowerlike micelles with micellar cores of hydrophobes to flower-loops of the hydrophilic main chain. Moreover, there is a critical percolation concentration aside the CAC where polymer viscosity increases. This arises from the formation of a network of micelles containing hydrophobes connecting together (Wang et al. 2016). However, the use of hydrophobically modified EUR polymers for polymer flooding is not known despite its enhanced rheological attributes. Similarly, hydrophobically modified ASE polymers made up of three components mainly methacrylic acid, ethyl acrylate, and a hydrophobic group is insoluble under low pH conditions. Therefore, its solubility under high $\mathrm{pH}$ conditions would be beneficial for polymer flooding in high salinity oil reservoirs. Overall, the use of hydrophobically associating EUR, HEC, and ASE for enhanced oil recovery is not well known. Currently, the domain on polymer research is focussed towards the application of HAPAM polymers for EOR operations. As a result, the remainder of this review would be focussed on hydrophobically associating polyacrylamide.

\section{Effect of Reservoir Conditions on Hydrophobically Associating Polymers}

As mentioned before, the rheological behavior of hydrophobically associating polyacrylamide is governed by CAC. The hydrophobic blocks on the polymer chain confer on it its unique solution properties. Accordingly, at low polymer concentrations, which represents the dilute region, the viscosity of the polymer is low (as well as its hydrodynamic volume). Here, intramolecular association dominates the rheological behavior. In contrast, high polymer concentration above the CAC (semi-dilute region) would bring about a sharp increase in polymer hydrodynamic volume due to the intermolecular association between polymer chains. Consequently, the viscosity of HAPAM is increased and application of these 
polymers would require that their solution properties arising from hydrophobic interactions withstand the conditions inherent in an oil reservoir.

\subsection{Effect of Salinity and Hardness}

Ordinarily, increasing concentration of salts and divalent ions causes a reduction in the viscosity of HPAM due to the screening effect of the cations present in solution. However, the rheological behavior of HAPAM polymers under increasing salinity and divalent ion concentration often exhibits different trends depending on a number of factors such as the type of hydrophobe, the molecular structure of the HAPAM polymer and polymer concentration (Jincheng et al. 2018). Deng et al. (2014) conducted the synthesis of acrylamide based associating polymer using sodium 2-acrylamido-2-methylpropanesulfonic sulfonate as the hydrophobic comonomer. The viscosity of a $1 \mathrm{wt} . \%$ solution of the prepared HAPAM polymer decreased with increasing $\mathrm{NaCl}$ concentration (up to $0.2 \mathrm{wt} \% \mathrm{NaCl}$ ) under various shear rates. Between 0.2 and $0.4 \mathrm{wt} \% \mathrm{NaCl}$, the viscosity of the associating polyacrylamide solution increased. Likewise, Quan et al. (2016), El-Hoshoudy et al. (2017) and Sarsenbekuly et al. (2017) reported similar trends with HAPAM polymers in solutions containing monovalent and divalent ions. According to El-Hoshoudy et al. (2017), acrylamide based poly (4-dodecyl-benzenesulfonate-3-[5-(butane-2-sulfonyl)-3-carbamoyl-1methyl-heptyl] imidazol-3-ium) showed an initial decrease in polymer viscosity with $\mathrm{NaCl}$ concentration after which the viscosity increased with increasing $\mathrm{NaCl}$ concentration. The same effect was also reported for HAPAM polymers reported by Sarsenbekuly et al. (2017) and Quan et al. (2016). This phenomenon associated with HAPAM polymers was attributed to:

a) Screening/Shielding Effect: The presence of cations in salts reduce the electric double layer and hydration layer thereby reducing the electrostatic repulsion between charged groups on the polymer chain (Quan et al. 2016; El-Hoshoudy et al. 2017; Sarsenbekuly et 
al. 2017). In effect, chain contraction is experienced and a reduction in the hydrodynamic volume of the polymer in solution. This initial effect was responsible for the reduction of the polymer viscosity.

b) Hydrophobic Associative Effect: A further increase in the concentration of salt and divalent ions would ensure contact of the hydrophobic groups on the polymer chain. The effect of this was the formation of aggregates of polymer chains (El-Hoshoudy et al. 2017). The impact of this aggregation of polymer chains was that it nullifies the initial screening effect, which brought about the reduction in the hydrodynamic volume of the polymer through a contraction. As a result, the polymer is stretched and its hydrodynamic volume was increased.

The various polymer solutions containing salts described above can simply be prepared by dissolving the polymer in an appropriate amount of salt/divalent ion solution. Other approaches include adding a sufficient quantity of salt to an already prepared polymer solution or adding salt water to the polymer solution. Nevertheless, the approach used in preparing HAPAM polymers both in aqueous and brine solutions has been demonstrated to affect the rheological behavior of the HAPAM polymers (Maia et al. 2005; Wever et al. 2011). Maia et al. (2005) synthesized an acrylamide- $N, N$-dihexylacrylamide copolymer and evaluated its rheological behavior under monovalent $\left(\mathrm{Na}^{+}\right)$ion concentration. The three procedures mentioned earlier were applied by the authors in evaluating how the mode of contact of HAPAM polymers with $\mathrm{Na}^{+}$ions affects its rheology. The copolymer exhibited different tolerances to $\mathrm{Na}^{+}$ions. Firstly, with the copolymer dissolved in salt solution, the viscosity of the polymer solution decreased with increasing $\mathrm{NaCl}$ concentration. This was ascribed to the screening effect of the cations on the charged moieties present on the polymer chain. Secondly, when salt powder was added to the copolymer solution, the viscosity increased up to a maximum after which there was a reduction. The authors in explaining why 
the viscosity passed through a maximum identified the presence of surfactant in solution. Thirdly, when salt water or brine solution was added to the polymer solution, the viscosity of the polymer increased with increasing salinity. The authors attributed this third phenomenon to "Easiness of Interaction" when salt and polymer exist already in solutions, which leads to the formation of a network of polymer chains. Al-Sabagh et al. (2016) evaluated the effect of divalent ions $\left(\mathrm{Ca}^{+}\right)$at $30{ }^{0} \mathrm{C}$ and shear rate of $6 \mathrm{~s}^{-1}$ on HAPAM polymers with different type and quantities of hyrophobic monomers. A general observation was that the associative effects of the polymers (or cation resistance) can only be maitained at low concentrations of divalent ions compared to monovalent ions. This was the case irrespective of the type of hydrophobic content of the polymer. This can be expalined in terms of the strong sheilding effect of divalent ions compared to monovalent ions. Asides the findings of the authors, there is limited understanding of this phenomenon associated with HAPAM polymers. In addition to the method of preparation, the concentration regime (dilute or semi-dilute) of hydrophobically associating polymers plays a role in its salt tolerance (Kamal et al. 2015). In general, the salt-thickening ability of associating polymers in brine solutions can be maintained up to a particular concentration of monovalent or divalent ion depending on the type of hydrophobic comonomer employed (Wyatt et al. 2011; Chen et al., 2012; Zhong et al. 2014; Kamal et al. 2015). However, beyond this salt concentration value, the polymer viscosity thins out with increasing salinity in the presence of monovalent and divalent ions. The ensuing effect sometimes is the precipitation of HAPAM polymers out of solutions (salting-out effect) and this can impact on the polymer concentration required. With polymer concentration often limited in high permeable reservoirs, improving the salt-thickening capability of hydrophobically associating polyacrylamide had resorted to cross-linking of the polymer chains (Zhong et al. 2014). The essence of cross-linking of HAPAM polymer chains is to: 
a) Offset the effect of having a long hydrophobic group on the polymer backbone which might minimize its solubility in solution.

b) Decrease the volume available per molecule without necessarily increasing the polymer concentration.

c) Ensure that salt-thickening capability of HAPAM polymers is enhanced (over a wide range of salinity) within a predetermined polymer concentration value in permeable formations.

The molecular conformation of the cross-linked polymer enables it to have an expanded configuration compared to linear associative polymers without side chains. This ensures the average diameter of the polymer aggregates is higher under monovalent or divalent conditions. Therefore, the salt-thickening capability of the associative polymer is increased when cross-linked. However, the resulting molecular weight of cross-linked polymers may be too high as control over the degree of crosslinking can be difficult to maintain. This may subsequently cause formation damage in sections of oil reservoirs with low permeability. With applied polymer concentration in most permeable formations constrained in order to ensure salt tolerance, a proper understanding of CAC under aqueous and high salinity conditions is required (Zhong et al. 2014). The salinity effect on the CAC of the some polymers from the work of Rashidi et al. (2010) are presented in Table 4. As seen from the table, the CAC of the polymers were observed to increase with the degree of salinity. The increment in CAC can be ascribed to an increase in charge density on the polymer chain which decreases polymer hydrodynamic volume. As such, a higher threshold value of CAC would be required for a meaningful hydrophobic associative effect to take place. To express this, a mathematical relationship by Hayahara and Takao (1968) can be used as shown in Equation (1):

$$
\mathrm{V}_{\mathrm{m}}=\frac{\mathrm{M}_{\mathrm{a}}}{\mathrm{C}_{\mathrm{c}} \mathrm{N}_{\mathrm{a}}}
$$


Where $V_{m}$ is the volume available per polymer chain, $M_{a}$ is the molecular weight of polymer, $\mathrm{C}_{\mathrm{c}}$ is the CAC of the polymer and $\mathrm{N}_{\mathrm{a}}$ is the Avogadro's number. An increase in the CAC, (denoted by $\mathrm{C}_{\mathrm{c}}$ ), would bring about a decrease in the volume available per polymer chain, $\mathrm{V}_{\mathrm{m}}$ and vice versa. When $V_{m}$ is reduced polymer chains come together and the hydrophobic associative effect is enhanced. This incremental effect of salinity on CAC was also validated by the work of Saeed et al. (2017). However, the implication of this on EOR operations would mean:

a) High polymer concentration would be needed, if not above the limit for EOR operations, and this could be detrimental to the economics of the flooding process;

b) Polymer injectivity would be affected and this is often constrained by formation fracture pressure.

Ultimately, a salt-tolerant HAPAM polymer is one whose thickening properties are enhanced under increasing salinity. However, the choice of a particular HAPAM for high salinity condition depends on a number of factors inherent in both the polymer architecture (and hence its synthesis method) and reservoir. As such, the applicability of associating polymers for EOR operations would essentially be specific to the reservoir conditions.

\subsection{Effect of Temperature}

Thermal effects on the rheological properties of HAPAM polymers have been reported widely in the literature (Taylor and Nasr El-Din, 1998; Hourdet et al., 2005; Al-Sabagh et al., 2016; Dai et al., 2017; Bai et al., 2018). Various HAPAM polymers with different hydrophobic moieties on the polymer backbone have been reported with diverse response under varied temperature conditions. However, the temperature dependence of HAPAM polymers is affected by the concentration regime (dilute and semi-dilute regime). When polymer concentration is less than the CAC of the HAPAM polymer, there is a decrease in polymer viscosity with increasing temperature. Yang et al. (2015) demonstrated this using 
synthesized hydrophobically associating cationic perfluorinated polyacrylamide (HACFP). The polymer viscosity at a concentration of $0.2 \mathrm{wt} . \%$ (< CAC value of $0.24 \mathrm{wt} . \%$ ) decreased with temperature over the range of $20-85{ }^{\circ} \mathrm{C}$. The authors attributed this phenomenon to weak intermolecular associative effect between hydrophobic groups in the dilute concentration regime $(\mathrm{C}<\mathrm{CAC}$, where $\mathrm{C}$ is polymer concentration). Besides the explanation offered by the authors, this could also be attributed to the intramolecular associative effect being an endothermic process under this concentration regime. Polymer chains would coil up under these conditions thereby reducing the hydrodynamic volume and hence the viscosity of the polymer solution. With further increase in temperature, the thermal induced motion of water molecules and the polymer chains would further strengthen the hydrodynamic volume reduction through clustering of coiled polymer chains hence further reducing the polymer viscosity. A similar phenomenon was reported for HAPAM modified with 2phenoxylethylacrylate by Dai et al. (2008) at a polymer concentration less than the CAC. A consensus in the literature on the thermal behavior of HAPAM polymers is that the viscosity of the polymers increase with temperature up to a maximum after which there is a decrease in viscosity with a further increase in temperature. Such a trend is obtainable when the polymer concentration exceeds the CAC i.e. semi-dilute concentration regime. El-Hoshoudy et al. (2017) revealed this fact with synthesized acrylamide based poly (4-dodecylbenzenesulfonate-3-[5-(butane-2-sulfonyl)-3-carbamoyl-1-methyl-heptyl] imidazol-3-ium) through evaluation of its thermal resistance between 25 and $100{ }^{0} \mathrm{C}$ at a concentration of 2 $\mathrm{g} / \mathrm{L}$ and a shear rate of 7.34 /s. The viscosity of the HAPAM polymer increased up to a maximum at $50{ }^{\circ} \mathrm{C}$ after which there was a decrease in viscosity up to $100{ }^{\circ} \mathrm{C}$. This can be explained by the endothermic driven process of hydrophobic intermolecular association between polymer chains in solution. This leads to a network/micro-domain of polymer chains with an increase in hydrodynamic volume with regards to polymer viscosity. When the 
temperature exceeds the $50{ }^{0} \mathrm{C}$ mark, thermal induced motion of the water molecules would weaken the super-aggregate structure formed by the hydrophobic interactions between the polymer chains thereby weakening the intermolecular association between the chains. The outcome of this is a reduction in polymer viscosity with increasing temperature. Equally, Lai et al. (2013), Zou et al. (2013) and Sun et al. (2015) reported a similar trend for synthesized HAPAM polymers poly (AM-NaAA-DNDA), cyclodextrin functionalized associating acrylamide, and poly (AM-AMC $\left.{ }_{12} \mathrm{~S}-\mathrm{DPP}\right)$ respectively. The maximum viscosity for the HAPAM polymers was obtained at $40{ }^{0} \mathrm{C}$ [for poly (AM-NaAA-DNDA)], $80{ }^{0} \mathrm{C}$ [for cyclodextrin functionalized associating acrylamide polymer] and $35{ }^{0} \mathrm{C}$ [for poly (AM$\mathrm{AMC}_{12} \mathrm{~S}$-DPP)]. Additionally, Gou et al. (2015) reported maximum viscosity at temperatures of 35 and $42{ }^{\circ} \mathrm{C}$ respectively for poly (AM-AA-NDS-NIMA) and poly (AM-AA-NIMA). Therefore, the type, amount and molecular composition of the hydrophobic comonomers employed in the synthesis of HAPAM polymers play a role in its temperature tolerance. Table 5 shows the maximum temperature tolerance of some HAPAM polymers in the semidilute concentration regime. The copolymerization of acrylamide with these hydrophobic comonomers is partly aimed at improving its temperature tolerance. However, some of the HAPAM arising from the copolymerization process may not achieve high polymerization activity and as a result experience low intrinsic viscosity and molecular weight (Zhong et al., 2014; Li et al., 2017). The implication of this is that the maximum temperature tolerance of some of these polymers may vary as indicated in Table 5. As such, thermo-thinning defects tend to set in beyond temperature values for maximum viscosity. Furthermore, the molar ratio of hydrophobic comonomers employed in the copolymerization process is in the range of 10 - $30 \%$ (Li et al., 2017). While an increment would improve the performance of the polymer, it may create additional cost for production. Temperature effect on the CAC of HAPAM is limited and not widely reported. Nevertheless, this may have a significant impact, in the same 
manner, as earlier reported for salinity effects. El-Hoshoudy et al. (2017) reported the temperature tolerance of synthesized acrylamide based poly (4-dodecyl-benzenesulfonate-3[5-(butane-2-sulfonyl)-3-carbamoyl-1-methyl-heptyl] imidazol-3-ium) at the critical aggregation concentration. However, there was no reported indication of its effect on the CAC of the polymer. A general understanding of this effect could be linked to the description given by Hourdet et al. (2005). The dynamics of the associative network formed by HAPAM polymers is tied to the strength of the hydrophobic interactions (as measured as the binding energy/energy barrier) between polymer chains. Accordingly, the Andrade's equation (Equation 2) can be applied to hydrophobically associating polymers, where the activation energy can be closely compared to the energy barrier.

$\eta=B e^{\left(\frac{E_{a}}{k T}\right)}$

Where $\eta$ is the polymer viscosity, $E_{a}$ is the activation energy $(\mathrm{kJ} / \mathrm{mol}), B$ and $\mathrm{k}$ are constants, $\mathrm{T}$ is the temperature in kelvin. The relationship between the CAC of associating polymers and the intrinsic viscosity is represented in Equation (3):

$\mathrm{C}^{*}=\frac{1}{[\eta]}$

Where the CAC is $\mathrm{C}^{*}$ and the intrinsic viscosity of the polymer solution $[\eta]$ is represented in Equation (4) where $\eta_{s}$ is the viscosity of the solvent:

$[\eta]=\lim _{C \rightarrow 0}\left(\frac{\eta-\eta_{s}}{\eta_{s}}\right)$

From the expressions in Equations (2) to (4), the dynamics of the hydrophobic association between polymer chains is dependent on temperature and the degree of hydrophobicity (which is described by the activation energy). Apparently, the outcome can be described in two ways: 
a) For a given degree of hydrophobicity, an increase in temperature would bring about a reduction in polymer viscosity, $\eta$, likewise the intrinsic viscosity, $[\eta]$. This would imply an increase in the critical aggregation concentration, $\mathrm{C}^{*}$. What this simply means is that a higher polymer concentration would be required to sustain the associative effect of the hydrophobic groups present in the polymer backbone.

b) Where the degree of hydrophobicity is increased, the energy barrier/activation energy is intensified likewise the intrinsic viscosity. As such, the critical aggregation concentration would decrease. However, polymers with a high degree of hydrophobicity would experience a larger drop in viscosity with temperature.

While these are plausible theoretical explanations to thermal effects on the CAC of associating polymers, further research into this trend would be beneficial where polymer injectivity is paramount. As previously stated, EOR involving the use of polymers requires concentration values set to a particular limit based on the economics of the project. In improving the thermal resistance of hydrophobically associating polymers, grafting of the copolymers with a temperature responsive side chain have been reported (Barker et al., 2003; Hourdet et al., 2005; Brassinne et al., 2014; Lee et al., 2015; Victor et al., 2016; Li et al., 2017). Such “smart polymers" are characterized by a critical association temperature (CAT) above which polymers self-assemble into hydrophobic microdomains (Hourdet et al., 2005; Li et al., 2017). In other words, there is a change in character from hydrophilicity to hydrophobicity (Li et al., 2017). This CAT is determined by the critical solution temperature of the graft monomer employed. $N$-isopropylacrylamide (NIPA) is a commonly employed monomer in preparing thermos-responsive polymers and it is characterized by a low critical solution temperature (LCST) (Oh et al., 2013; Zhang and Hoogenboom, 2015; Victor et al., 2016; Badi, 2017; Santis et al., 2017). The LCST represents the temperature value below which components of a mixture are miscible. In addition, some monomers are characterized 
by an upper critical solution temperature (UCST) above which components in the mixture are miscible in all proportions (Badi, 2017; Niskanen and Tenhu, 2017). The smart tuning of the viscosity of these polymers ensures that they are applicable in high-temperature oil reservoirs. However, the critical solution temperature values of the grafted polymers are dependent on the degree of polymerization, branching and polydispersity. As such, some HAPAM molecules grafted with thermos-responsive comonomer may still exhibit low molecular weight with high polymer concentration needed for thermo-thickening. Furtherance to this, Li et al. (2017) pointed out that an expensive coupling agent is necessary for the polymerization process of thermo-responsive polymers and reactions are conducted at low polymer loadings. Increasing the hydrophobic length would strengthen intermolecular associative effect for high-temperature applications, however, there is a limit that would ensure polymer solubility is maintained. Also, some grafted polymers may exhibit an LCST lower than the UCST. This simply means such polymers can only exhibit thermo-thickening over a particular temperature interval while thermo-thinning will set in at lower and higher temperatures. For polymers exhibiting both LCST and UCST, a favorable disposition is for LCST to be higher than the UCST. This would ensure the temperature tolerance of the polymer at high temperatures. Some thermo-responsive associating polymers may require some stimulating effect for thermal response to take place between grafts on the polymers ( $\mathrm{Li}$ et al., 2017). This may limit the acceptance of thermo-responsive hydrophobically associating polymers in the oil and gas industry as this would contribute to cost. The long-term stability of HAPAM polymers in porous media depends on the sustainability of its associative characteristics under different conditions of temperature, salinity, $\mathrm{pH}$ and divalent ion concentration. In addition, the CAC which is a critical parameter of associative polymers have been reported in literature to be susceptible to reservoir conditions (El-Hoshoudy et al., 2017; Saeed et al., 2017). However, an explanation for the susceptibility of the CAC to 
different reservoir conditions could mean that intramolecular interactions could transit to intermolecular interactions and vice versa. Recently, Guo et al. (2016) showed this possibility by conducting core flooding through three serially mounted cores with very similar rock properties (permeability and porosity). It was observed that for associative polymers namely HNT-3.28 and HNT-4.32 (containing 3.28 and 4.32 mol \% hydrophobic monomer respectively), the resistance factors $(\mathrm{RF})$ of the polymers were much greater in the second and third cores compared to the first core. Plausible explanation given by the authors was the conversion of intramolecular interactions to intermolecular interactions due to elongational or extensional flow in the porous media. However, this transition between the two interactions depends on the hydrophobic monomer content. It was observed that similar trend of transition was not observed with associative polymers HNT-1.1 and HNT-2.2 (containing 1.1 and 2.2 mol \% hydrophobic monomer) respectively. It was put forward by the authors that this may be due to low intramolecular interactions such that any transition to intermolecular interaction has been counteracted by polymer-rock interaction such as adsorption. Similarly, this trend of intramolecular to intermolecular transition and vice versa may explain why the CAC of associative polymers change under different reservior conditions. However, an understanding of this phenomenon could eventually explain the stability of associative polymers under different reservior conditions.

\subsection{Effect of pH}

The charged nature of polyelectrolytes makes it easily affected by the degree of ionization of solution (Wever et al., 2011). For polyelectrolytes with more than one negative group (polyanion), they experience high viscosity at high $\mathrm{pH}$ and low viscosity at low $\mathrm{pH}$ (Wever et al., 2011). Whereas, for polycations, they experience low viscosity at high $\mathrm{pH}$ and high viscosity at low pH (Wever et al., 2011). However, typical polyelectrolytes are polyanionic in nature with $\mathrm{pH}$ response as earlier described for polyanions. Zhou et al. (2001) showed this 
with polyacrylic acid with the polymer viscosity increasing with $\mathrm{pH}$ up to a maximum at $\mathrm{pH}$ values between 8 and 9. The decrease in the viscosity value beyond the $\mathrm{pH}$ value was attributed to the salting effect, which is similar to what is obtained from $\mathrm{NaCl}$. The response of hydrophobically associating polymers to $\mathrm{pH}$ is rather complex (Zhou et al., 2001). A balance between electrostatic repulsion between charged moieties on the chain and hydrophobic interactions characterizes the $\mathrm{pH}$ responsiveness of HAPAM (Branham et al., 1996; Smith and McCormick, 2001; Zhou et al., 2001; Zhuang et al., 2001; Huaiping et al., 2008; Wever et al., 2011). In other words, the viscosity of hydrophobically associating polymers with an increase in $\mathrm{pH}$ is dependent on the transition between intramolecular and intermolecular interaction. In demonstrating this effect, Zhou et al. (2001) synthesized a copolymer of acrylic acid and 2-(N-ethylperfluorooctanesulfoamido) ethyl acrylate or 2-(Nethylperfluorooctanesulfoamido) ethyl methacrylate. It was observed that two increments in polymer viscosity were achieved. Beyond a $\mathrm{pH}$ value of 4 , polymer viscosity increased to a maximum in the range of $5-6$. Further increment leads to a decrease in polymer viscosity followed by another increase beyond $\mathrm{pH}$ of 11 . This behavior of the polymer is captured in Figure 4. An explanation for this trend can be grouped into three categories according to the authors:

a) Between $\mathrm{pH} 5-7$, the ionic character of the polyacrylic acid copolymers is not fully developed and as such hydrophobic interactions occur in solution.

b) Between $\mathrm{pH} 7-11$, the polyelectrolyte character of the copolymers is developed with chain expansion. However, a lack of mobility prevents the hydrophobic interaction.

c) Beyond $\mathrm{pH} 11$, the screening effect similar to what is experienced under increasing salinity allow for the exposure of hydrophobic groups for associative interaction.

Although, the authors did not discuss the $\mathrm{pH}$ range of $1-4$, however under this condition the intramolecular associative effect is dominant hence the viscosity of the HAPAM is low 
without any noticeable increase. Similarly, Zhuang et al. (2001) demonstrated the above trends highlighted from (a) to (c) using poly (acrylate-co-alkyl acrylate) as shown in Figure 5. For the poly (acrylic acid) (PAA) polymer, under low $\mathrm{pH}$ conditions (acidic conditions), there is a low charge density due to the undissociated state of the carboxylic groups on the polymer chain. This minimizes electrostatic repulsion hence chain retraction resulting in a decrease in polymer viscosity. As the $\mathrm{pH}$ increases, there is a gradual increase in charge density due to the gradual dissociation of the carboxylic groups on the polymer chain. At maximum viscosity, there is a complete dissociation of the carboxylic groups and a further increase in $\mathrm{pH}$ would result in a salt effect on the polymer. This is similar to the effect reported by Zhou, et al. (2001) on PAA polymers in Figure 4. However, the modified PAA copolymers i.e. poly (acrylate-co- alkyl acrylate) by Zhuang et al. (2001) showed the same trend described by Zhou et al. (2001). The behavior of the associating polymer is essentially a balance between electrostatic repulsion between charged moieties on the chain and hydrophobic interactions.

\section{Inaccessible Pore Volume (IPV) of Associating Polymers}

The IPV can be described as the fraction of the rock pore volume which remain inaccessible to the polymer due to the polymer size (Pancharoen et al., 2010; Sheng, 2011; Al-Hajri et al., 2018; Torrealba and Hoteit, 2019). According to Sheng (2011), when polymer molecular sizes are larger than some pores in a porous medium, the polymer molecules cannot flow through those pores. Consequently, the volume of those pores that cannot be accessed by polymer molecules is called the IPV (Sheng, 2011). Asides the polymer size, this phenomenon depends on salinity, divalent ion concentration, rock surface effect, temperature, polymer charge and concentration and the pore-size distribution of the rock (including deadend pores) (Al-Hajri et al., 2018; Torrealba and Hoteit, 2019). Pancharoen et al. (2010) studied the effect of different associating polymers on the IPV of a sand-packed column with an absolute permeability of $21.6 \mathrm{D}$. The molecular weight of associating polymers was 
identified as a key factor which influence the IPV of associating polymers. High molecular weight associating polymers are characterized with large molecular volume and more hydrophobic regions on the polymer chain. As such, associating polymers with large molecular weight would result in polymer chains with large molecular clew dimension compared to pore throat sizes. According to the experimental work of Pancharoen et al. (2010), low molecular weight associating polymers displayed 12 and $20 \%$ of IPV using superposition and simulation methods respectively. However, the high molecular weight associating polymers showed IPV between $33-49 \%$ depending on the approach used. An explanation for this could still be explained in terms of the hydrophobic interactions which increases with polymer molecular weight. In like manner, the concentration regime of associating polymers eithier dilute or semi-dilute can influence the IPV. At concentrations representative of dilute regime, hydrophobic interactions are absent, polymer resistance factor is reduced and as such injectivity increasd thereby reducing IPV. However, when polymer concentration represents the semi-dilute regime, hydrophobic interactions dominate and polymer resistance factor is increased and as such injectivity decreased thereby increasing IPV. The IPV represents one of many mechanisms of polymer transport in porous media and where this is dominat, it may lead to the process of polymer accelaration. This would occur when polymer solution is injected at salinity lower than the reservoir salinity. However, where polymer adsorption is dominant, the process of polymer transport is different as discussed below.

\section{Adsorption Properties of Associating Polymers}

The size of associating polymer cluster depends on polymer concentration and the level of hydrophobe content that can lead to polymer adsorption and retention in porous media (Taylor and Nasr El-Din, 1998). This is particularly the case when the hydrophobe distribution along the polymer chain is blocky rather than random. In the case of block 
distribution of hydrophobe content, the concept of multilayer adsorption has been proposed as an explanation (Page et al., 1993; Volpert. et al., 1998; Dupuis et al., 2011; Kamal et al., 2015; Zhao et al., 2017). The adsorbed layer of the associating polymer has a segment of the hydrophobic group interacting with the rock surface, while another portion of the hydrophobic group tends to interact with other polymer chains forming another layer of adsorption. As a result, an increase in the polymer concentration of associating polymer would continuously increase the level of polymer adsorption on the rock surface. Most of the experimental studies on HAPAM have focused on using sand-pack columns. As such, the mechanism of polymer-rock interaction for hydrophobically modified polymers may differ for calcite, sandstone and dolomite reservoirs. El-Hoshoudy et al. (2015) reported the interaction of associative polymers with sandstone rocks. From Zeta potential measurements, the polymers exhibited values of -50.3 and $-21.8 \mathrm{mV}$ with an average value of $-46.3 \mathrm{mV}$. Thus, such associative polymers are capable of causing a wettability alteration on positively charged sandstone reservoirs during polymer flooding processes. However, at a $\mathrm{pH}$ value greater than 2, it was reported that sandstone rock can exhibit a negatively charged surface in which the positively charged nitrogen bases can adsorb on rock surface and alter wettability (El-Hoshoudy et al., 2015). In addition, Chiappa et al. (1999) reported the effect of polymer charge (anionic, weakly anionic and cationic) from a $2 \% \mathrm{KCl}$ solution on its adsorption on a quartzite rock surface which was negatively charged at $\mathrm{pH}$ greater than 2 . It was obvious from their findings that polymer adsorption increases from anionic to weakly anionic to cationic polymers. However, when these polymers were exposed to a reservoir sand (49wt.\% Quartz and 21 wt.\% Calcite), the anionic polymer exhibited negligible adsorption phenomenon while adsorption increased form the weakly ionic to the cationic polymer. It should be noted that calcite has a positively charged surface at $\mathrm{pH}$ values less than 9.5. Therefore, polymer intercation with rock surface may reflect a much more complex behavoir 
at the calcite surface. The presence of divalent ions can enhance the adsorption of anionic polymers onto a quartzite surface which can be achieved in two ways (Chiappa et al., 1999). Firstly, the divalent ion creates a link (or act as a bridge) between the anionic polymer and the negatively charged quartz surface. Secondly, the divalent ions can neutralize part of the negative sites on the anionic polymer thereby reducing electrostatic repulsion. Similarly, the adsorption of crude oil tends to reduce the tendency of polymer-rock interaction (Chiappa et al., 1999; Taheri-Shakib et al., 2019(a); Taheri-Shakib et al., 2019(b)). Quan et al. (2019) reported the use of HAPAM polymers in the acidification process of carbonate rocks. The adsorption of the associative polymer was such that it forms a protective film on the carbonate rock. The authors reported that the adsorption and desorption of associative polymers on the carbonate surface tends to influence the reaction rate between the acid and the carbonate. However, after the desorption process at the end of the reaction, small amounts of the associative polymers remain on the rock surface thereby creating cracks and voids (Figure 6). The adosrption isotherm of HAPAM polymers does not follow the classical approach which is often characterized by a plateau region. This is often attributed to the continous interaction between the hydrophobic regions of the polymer chains in solution. Concerning this, Volpert et al. (1998) reported on the interaction between HAPAM polymers and an alumina silicate surface. The adsorption isotherm of the HAPAM was characterized by a continuous increase in the adsorbed polymer and the absence of a plateau region. This phenomenon was explained in terms of classical multilayer adsorption which arises due to the hydrophobic interaction between polymer chains. However, recent studies on the rock adsorption (in sand-pack column) phenomenon associated with hydrophobically modified polymers have been attributed to some "minor polymeric species" (Dupuis et al., 2011; Seright et al., 2011). This implies that for hydrophobically associating polymers, adsorption does not mean the deposition of a substantial quantity of polymer molecules from solution to 
the rock surface. Accordingly, Dupuis et al. (2010) experimentally showed that the classical theory of multilayer adsorption does not apply to hydrophobically associating polymers. Rather, adsorption of hydrophobically associating polymers is controlled by the presence of "minor polymeric species". The authors injected an associating polymer with sulfonated polyacrylamide backbones and alkyl hydrophobic side chains into a cylindrical chamber with granular packs. As expected, a high resistance factor was obtained with the associating polymers. However, core-plugging did not take place as evident from the stabilization trend obtained from the resistance factor curves and no loss in viscosity of the polymer effluent. The polymer effluent was re-injected into a fresh core and resistance factor values were stable with no increase. According to Dupuis et al. (2011) and Seright et al. (2011), removal of these "minor polymeric species" with an appropriate filtration method without degrading the thickening capability of the polymer will ensure less adsorption. However, selection of an appropriate filtration method, which will ensure that the associating polymers do not lose their viscous properties may be challenging. Moreover, investigating the origin of these "minor polymeric species" would help understand how to properly design the synthesis and treatment process of hydrophobically associating polymers. Core flooding experiments carried out show an irreversible reduction in permeability without filtration of the precursor polymer solution. The resistance to adsorption of associating polymers can also be improved by using hydrophobes, which contain sulfonate groups (Taylor and Nasr El-Din, 1998; Seright et al., 2011; Wever et al., 2011). The use of 2-acrylamido-2-methyl propane sulfonate (AMPS) as a comonomer in the modifying polyacrylamide have been reported to produce less adsorption compared to HPAM polymers. However, this phenomenon appears to be peculiar with associating polymers made of 2-acrylamido-2-methyl propane sulfonate. Other factors such as salinity may influence the adsorption of associating polymers in porous media (Rashidi et al., 2009; Li et al., 2016; Akbari et al., 2017; Amirian et al., 2018). This may 
manifest in the form of ion competition with polymer molecules for adsorption sites and may result in less adsorption (Torrealba and Hoteit, 2019). It has been reported that where polymer adsorption is the prevailing transport mechanism in porous media, an injection of polymer solution at salinities lower than that of the reservoir would lead to polymer retardation where the salinity front accelerates faster than the polymer front.

\section{Injectivity of Associating Polymers and Permeability Reduction.}

Polymer injectivity can be predicted and monitored from values obtained for resistance factor (RF) and residual resistance factor (RRF) (Al-Shakry et al., 2019). The injectivity of associating polymers is low compared to conventional HPAM polymers and is characterize by large RFs (Seright et al., 2011; Azad and Trivedi, 2017). Furthermore, this low injectivity can be attributed to the nature of the polymer hydrophobic interaction which is concentration dependent (Dupuis et al., 2011; Xie et al., 2016; Azad and Trivedi, 2017). Azad and Trivedi (2017) carried out an injectivity study on associative polymers in comparison with HPAM polymers. It was observed that at a concentration of $2000 \mathrm{ppm}$, the associative polymers exhibited higher RFs than HPAM polymers at the concentration for all shear rates studied. Furthermore, the concentration value of $2000 \mathrm{ppm}$ represents the CAC of the associative polymer and the polymer showed decreased resistance for values at high shear rates. The decreased values of the RFs can be explained in terms of a transition of the associative effect from intermolecular to intramolecular interaction at high shear rates (Seright et al., 2011; Reichenbach-Klinke et al., 2016; Azad and Trivedi, 2017). However, at a concentration of $1000 \mathrm{ppm}$ for the associative polymers and HPAM, the RFs exhibited by both polymers were similar. For the associative polymer, this could be explained by intramolecular interaction dominating the rheology of the polymer. On the other hand, the amount and type of hydrophobe content in the polymer could also play an important role on the injectivity of associative polymers. Reichenbach-Klinke et al. (2016) investigated the performance of 
different associative polymers in terms of molecular weights and hydrophobic contents. The RF and viscosity were observed to increase with hydrophobic content and the reverse was the case with polymer injectivity (Seright et al., 2011; Reichenbach-Klinke et al., 2016; Azad and Trivedi, 2017). However, in oil saturated cores, it has been reported that the presence of oil weakens the intermolecular interactions with the degree of weakening is dependent on the hydrophobic content (Reichenbach-Klinke et al., 2016). Also, the presence of surfactants tend to reduce the high RF of associative polymers by competeing with the hydrophobic interactions thereby creating a surfactant-polymer interaction. Equally important from the work of Reichenbach-Klinke et al. (2016) is the impact of associative polymer on permeability reduction. Using polymer concentrations of $1000 \mathrm{ppm}$ and $2000 \mathrm{ppm}$ for the associative polymer and HPAM respectively showed that associative polymers have higher values for the RRF compared to HPAM. This was explained in terms of the mechanism of multilyer adsorption which is further enhanced by hydrophobic interactions. However, this phenomenon of multilayer adsorption remained debatable as shown by the works of Dupuis et al. (2011) and Seright et al. (2011) who attributed the permeability reduction to the presence of some "minor polymeric species". Therefore, permeability reduction by associative polymers depends on the type of hydrophobic comonomer that make up the polymer chain. In like manner, at a concentration of $1000 \mathrm{ppm}$, the HPAM showed higher values for the RRF compared to the associative polymer. This implies that the dilute concentration regime where intramolecular interaction dominates ensures that the RRF is low. Under these circumstances discussed, it is obvious that the properties of associative polymers can be tuned and adjusted to achieve the desired injectivity, propagation, RF and RRF. Furtherance to this, the mechanism of polymer-rock interaction (IPV and adsorption) as discussed earlier can be employed in improving the injectivity and propagation of associative polymers as proposed by Torrealba and Hoteit (2019). The authors proposed a 
compositionally-tuned polymer injection process which takes into account polymer transport under salinity, adsorption and IPV. This specifically takes into account polymer retardation and acceleration effects arising from adsorption and IPV respectively. The proposed injection scheme appears viable under simulation however, experimental study is still required in validating the outcome. The application of this study to associative polymers would require optimizing in terms of slug composition, injection cycle size and number of cycles.

\section{Interfacial Tension, Foam Stability and Emulsion Properties of Associating Polymers.}

A challenge associated with polymer flooding is the separation of water from crude oil. This difficulty is traced to the interfacial tension (IFT) characteristics of polymers to enhance the stability of crude oil emulsions (Deng et al., 2002; Meiqin et al., 2008; Pancharoen, 2009; Pancharoen et al., 2010; Al-Sabagh et al., 2016). The interfacial tension characteristics of associating polymers can be attributed to the distribution of both hydrophilic and hydrophobic blocks along the polymer backbone (Pancharoen, 2009; Pancharoen et al., 2010). According to Pancharoen et al. (2010), the hydrophobic groups on the polymer backbone align themselves in the oil phase which contains interfacial active components such as asphaltenes and resins while the hydrophilic part remain in the aqueous phase. This behaviour of associating polymers reduces the contact area between oil and water thereby reducing the interfacial tension and enhancing crude oil emulsion stability. Comparison with low molecular weight surfactants show that the abilities of these polymers in reducing IFT was less. Therefore, the authors pointed out the magnitude of this IFT reduction does not appear to be significant enough to contribute to added oil recovery. However, the strength of the emulsion stability effect of associative polymers depend on a number of factors such as type of associative polymer and polymer concentration. Meiqin et al. (2008) investigated the effect of polymer concentration on the interfacial tension caharacteristics of associative polymers. The measured interfacial shear viscosity of the water-oil film was used to 
characterise stability of the water-oil emulsion. It was observed that the interfacial shear viscosity of the oil-water film increased with associative polymer concentration hence its emulsion stability. Consequently, the rate of demulsification and the rate of oil-water separation would decrease with increased polymer concentration. Hence, the strength of the emusion stability caused by increased polymer concentration can be explained in terms of increased number of hydrophobic groups available to the oil phase. As such, IFT reduction does not contribute to the mechanism by which associating polymers improve the recovery of oil (Pancharoen et al., 2010). However, Reichenbach-Klinke et al. (2016) reported that additional oil recovery using associative polymers could take place with a combination of IFT reduction and mobility reduction. While this remain debatable, the increased oil-water emulsion stability arising from the application of associating polymers remains a challenge towards its application.

A foam can be described as having a gas phase dispersed in a liquid phase and often used in improving the mobility of gas (such as $\mathrm{CO}_{2}$ ) during EOR operations (Zhang et al., 2015; Xu et al., 2016; Ahmed et al., 2017). However, it is very important that the foam remains stable in the presence of oil as its longevity is what determines it efficiency. Ahmed et al. (2017) compared the use of conventional HPAM polymer with an associative polymer in the preparation of polymer enhanced foams (PEFs) with polymer concentration kept at $2000 \mathrm{ppm}$ and operating temperature and pressure at $80{ }^{\circ} \mathrm{C}$ and 14.5 psi respectively. Figures 7 and 8 show the comparison between HPAM and HAPAM polymers in terms of foam stability and foam volume respectively. The stability of the PEF was observed to be more pronouced using an associative polymer compared to HPAM polymer. This can be explained by the enhanced thickening ability (arising from hydrophobic interactions) of the associative polymer compared to HPAM. This enhanced thickening effect of the associative polymer tend to limit gas diffussion thereby enhancing foam stability through a gradual reduction in foam volume. 
However, the thickening capability of associative polymers differs for different hydrophobic content and under varying reservior conditions. Hence, enhancing the preformance of PEFs would require optimizing for different hydrophobe content and reservior conditions.

\section{Effect of Reservoir Heterogeneity on Associating Polymers}

The influence of polymer concentration and reservoir heterogeneities on polymer flooding performance are among paramount factors that determines the success of the oil recovery process (Han et al., 2006; Wei et al. 2007; Wassmuth et al., 2012; Patokina, 2015; Xie et al., 2016). Reservoir heterogeneities arise from the depositional history of the oil formation and this creates a difference in physical properties between the high permeability layer and low permeability layer (Xie et al., 2016). For a homogenous reservoir with uniform rock properties, the propagation of hydrophobically associating polymers depends on polymer concentration (Wassmuth et al., 2012). Furthermore, the state of molecular interaction/aggregation of associating polymers for mobility control can be regulated by changing the polymer concentration. Xie et al. (2016) evaluated the applicability of hydrophobically associating polymers in a heterogeneous reservoir system. It was confirmed by the authors that there exists compatibility between polymer molecular aggregation/association and pore-throat size. In other words, there exists a matching relationship between the size of an associated polymer cluster and the size of the pore-throat of the reservoir. Where the size of the associated polymer cluster matches well with the porethroat size, the pressure drop was observed to be stable as pore volume increased. Alternatively, at a given polymer concentration, there could be a mismatch between the size of the cluster and the pore-throat, therefore, the pressure drop due to polymer injection increases with pore volume. As such, a heterogeneous reservoir provides a scenario where rock properties play an important role along with the polymer concentration (Wassmuth et al., 2012; Xie et al., 2016). A change in polymer concentration will control the mobility of 
polymer solution in the different permeable layers of the reservoir. Accordingly, Xie et al. (2016) considered the following as crucial for associating polymer in a heterogeneous reservoir:

a) The size of the associating polymer cluster which is regulated from polymer concentration thereby ensuring passage through low pore-throat zones.

b) Reservoir fluid diversion arising from polymer jam/retention in high permeability zone. This is a result of the size of the associating polymer cluster.

Thus, the different molecular association between polymer molecules and the size of the associating polymer cluster arises from varied polymer concentrations. The size of the associating polymer cluster at a given concentration needs to be optimally matched with the average heterogeneities and permeability of the different layers in the reservoir. The essence of optimally matching the size of the aggregates arising from the associating polymer clusters and the reservoir heterogeneities can be tied to the following:

a) High polymer concentration would be needed, if not above the limit for EOR operations, and this could be detrimental to the economics of the flooding process;

b) For a heterogeneous reservoir, finding an optimum concentration for associating polymers would help prevent the occurrence of a profile reversal where polymer mobility is enhanced in the permeable layer with little residual oil.

c) In addition, polymer injectivity would be affected and this is often constrained by formation fracture pressure. Furthermore, high polymer injection pressure can make associating polymers lose their space-network structure resulting in a reduced hydrodynamic size for the polymer molecules. 


\section{Conclusion and Recommendations}

The last decade of research on hydrophobically associating polymers has witnessed the development of polymers tolerant to a wide range of conditions reminiscent of an oil reservoir. The conditions of the reservoir would properly define the required properties of these associating polymers. This, in turn, would determine the synthesis method/procedure, molecular structure and type of hydrophobic comonomer to be employed. In this regard, the rheological behavior of hydrophobically associating polymers cannot be entirely linked to the molecular structure in aqueous solution alone. Rather, the behavior is a combination of the influence of oilfield parameters (such as temperature, salinity, ion concentration, $\mathrm{pH}$ and reservoir heterogeneity) and the molecular structure of the polymer (arising from the synthesis method/procedure and the hydrophobic comonomer used). Therefore, finding an optimal scenario between the oilfield parameters and the molecular architecture of the polymer could define an appropraite use for associating polymers. This is imperative because a predominantly weak associative effect would not necessarily guarantee the needed rheological impact in terms of recovery efficiency even if polymer injectivity is not affected. Also, an excessively strong associative effect may affect polymer injectivity and propagation even if the needed polymer mobility and oil recovery are obtained. Consequently, the following recommendations have been made based on the issues identified in this review:

a) The sensitivity of the critical aggregation concentration of associating polymers to oilfield conditions such as temperature, salinity/hardness and $\mathrm{pH}$. The impact of this on the performance of the polymers would be a key area of investigation.

b) Sustaining and maintaining the associative effect of these polymers (long-term stability) during propagation in porous media while taking into consideration the sensitivity of the critical aggregation concentration as highlighted in (a). 
c) The impact of the associative effect on polymer injectivity as measured by polymer concentration above the critical aggregation concentration. An understanding of its effect on the onset of shear thickening in porous media is important and has the potential to be a key focus of research activities in this field.

d) The possibility of a change in the critical aggregation concentration of the produced associating polymer and what this change means on the solution properties of the polymer.

e) Investigation of the effect of injection rate on the compatibility of the size of associating polymer cluster and reservoir pore-throat. Previous studies have focused on the use of a single injection rate in optimizing solution properties of associating polymers and reservoir heterogeneity.

f) Investigation of the use of brackish water in the preparation of associating polymer solution. This study can help in investigating the influence of wastewater mineralization and hardness on the properties of hydrophobically associating polymers.

g) Investigation of the origin of the "minor polymeric species" connected to hydrophobically associating polymers. These species are often tagged as "pre-gel aggregates", however, understanding how to properly design the synthesis and treatment process of these hydrophobically associating polymers would reduce the likely occurrence of permeability impairment.

\section{Nomenclature}

\section{Abbreviations}

\section{AA Acrylic Acid}

$\mathrm{AMC}_{12} \mathrm{~S} \quad$ 2-(acrylamido)-dodecanesulfonic acid

AMPS 2-acrylamido-2-methyl propane sulfonate

ASE Alkali Swellable Emulsion 
CAC Critical Aggregation Concentration

DOAC N,N-dimethyloctadeyl allyl ammonium chloride

DPP 1-(4-dodecyloxy-phenyl)-propenone

EOR Enhanced Oil Recovery

EUR Ethoxylated Urethane

FTIR Fourier Transform Infrared

HEC Hydroxyethylcellulose

HAPAM Hydrophobically Associating Polyacrylamide

HPAM Hydrolyzed Polyacrylamide

HRTEM High Resolution Transmission Electron Microscope

IFT Interfacial Tension

LCST Lower Critical Solution Temperature

NDS 3-(diallyl-amino)-2- hydroxypropyl sulfonate

NIMA 3-(2-(2-Heptadec-8-enyl-4,5-dihydro-imidazol-1-yl)ethylcarbamoyl)acrylic acid

NIPA $\quad N$-isopropylacrylamide

NMR Nuclear Magnetic Resonance

OOIP Original Oil in Place

PAM Polyacrylamide

PAA Poly Acrylic Acid

PEF Polymer Enhanced Foam

RF Resistance Factor

RRF Residual Resistance Factor

PEG Poly Ethylene Glycol

SSS Sodium 4-styrenesulfonate 


$\begin{array}{ll}\text { TEM } & \text { Transmission Electron Microscope } \\ \text { UCST } & \text { Upper Critical Solution Temperature } \\ \text { B and k } & \text { Parameter Constants } \\ \mathrm{Ca} & \text { Capillary Number } \\ \mathrm{C} & \text { Polymer Concentration } \\ \mathrm{C}_{\mathrm{c}} \text { or } \mathrm{C}^{*} & \text { Critical Aggregation Concentration } \\ \mathrm{E}_{\mathrm{a}} & \text { Activation Energy } \\ \mathrm{M}_{\mathrm{a}} & \text { Molecular Weight of Polymer } \\ \mathrm{N}_{\mathrm{a}} & \text { Avogadro's number } \\ {[\eta]} & \text { Intrinsic Viscosity } \\ \eta_{\mathrm{s}} & \text { Solvent Viscosity } \\ \mu \text { or } \eta & \text { Polymer Viscosity } \\ \mathrm{T}_{\mathrm{m}} & \text { Temperature } \\ \gamma & \text { Volume Occupied per Polymer Chain } \\ & \end{array}$

\section{Acknowledgment}

The authors would like to acknowledge the financial grant (PTDF/ED/PHD/ARO/1387/18) of the Petroleum Technology Development Fund (PTDF) Nigeria for this research work.

\section{Conflict of Interest}

The authors have no conflict of interest to declare.

\section{References}

Abbas, S., Sanders, A. W., \& Donovan , J. C. (2013). Applicability of Hydroxyethylcellulose Polymers for Chemical EOR. SPE Enhanced Oil Recovery Conference. Kuala Lumpur: Society of Petroleum Engineers. 
Abidin, A. Z., Puspasari, T., \& Nugroho, W. A. (2012). Polymers for Enhanced Oil Recovery Technology. Procedia Chemistry, 4, 11-16.

Afolabi, R. O. (2015). Effect of Surfactant and Hydrophobe Content on the Rheology of Poly(acrylamide-co-N-dodecylacrylamide) for Potential Enhanced Oil Recovery Application. American Journal of Polymer Science, 5(2), 41 - 46.

Ahmed, S., Elraies, K. A., Tan, I. M., \& Hashmet, M. R. (2017). Experimental investigation of associative polymer performance for $\mathrm{CO} 2$ foam enhanced oil recovery. Journal of Petroleum Science and Engineering, 157, 971-979.

Akbari, S., Mahmood, S. M., Tan, I. M., Bharadwaj, A. M., \& Hematpour, H. (2017). Experimental Investigation of the Effect of Different Process Variables on the Viscosity of Sulfonated Polyacrylamide Copolymers. Journal of Petroleum Exploration and Production Technology, 7, 87-101.

Akbulut, M., \& Temizel, C. (2017). Technology Update: Adjustable, Supramolecular Viscosity Modifiers as Displacement Fluids in EOR. Journal of Petroleum Technology, 69(4), 1-3.

Algi, M. P., \& Okay, O. (2014). Highly Stretchable Self-Healing Poly(N,Ndimethylacrylamide) Hydrogels. European Polymer Journal, 59, 113-121.

Al-Hajri, S., Mahmood, S. M., Abdulelah, H., \& Akbari, S. (2018). An Overview on Polymer Retention in Porous Media. Energies, 11(10), 1-19.

Al-Sabagh, A. M., Kandile, N. G., El-Ghazawy, R. A., Noor El-Din, M. R., \& El-Sharaky, E. A. (2016). Solution Properties of Hydrophobically Modified Polyacrylamides and their Potential Use for Polymer Flooding Application. Egyptian Journal of Petroleum, $25,433-444$.

Al-Shakry, B., Skauge, T., Shiran, B. S., \& Skauge, A. (2019). Polymer Injectivity: Investigation of Mechanical Degradation of Enhanced Oil Recovery Polymers using In-Situ Rheology. Energies, 12, 49-74.

Amirian, E., Dejam, M., \& Chen, Z. (2018). Performance Forecasting for Polymer Flooding in Heavy Oil Reservoirs. Fuel, 216, 83-100.

Austad, T., Ekrann, S., Fjelde, I., \& Taugbol, K. (1997). Chemical Flooding of Oil Reserviors Part 9. Dynamic Adsorption of Surfactant onto Sandstone Cores from Injection Water with and without Polymer Present. Colloids and Surfaces A: Physiochemical and Engineering Aspects, 127(1), 69-82.

Azad, M. S., \& Trivedi, J. J. (2017). Injectivity Behaviour of Copolymer and Associative Polymers Decoded using Extensional Viscosity Characterization: Effect of Hydrophobic Association. SPE Western Regional Meeting. California: Society of Petroleum Engineers.

Badi, N. (2017). Non-linear PEG-based Thermoresponsive Polymer Systems. Progress in Polymer Science, 54-79, 66. 
Bai, Y., Shang, X., Wang, Z., \& Zhao, X. (2018). Experimental Study on Hydrophobically Associating Hydroxyethyl Cellulose Flooding System for Enhanced Oil Recovery. Energy and Fuels, 32, 6713-6725.

Bains, G., Patel, A. B., \& Narayanaswami, V. (2011). Pyrene: A Probe to Study Protein Conformation and Conformational Changes. Molecules, 16, 7909-7935.

Bang, F., Cech, T., \& Gebert, S. (2017). Poly(methacrylic Acid-co-Ethyl Acrylate): Comparing Three Different Grades in Regard to Preparation and Functionality Features in Enteric Release Film-Coating Applications. 2nd European Conference on Pharmaceutics. Krakow, Poland: Pharma Solutions Sales Europe.

Barker, I. C., Cowie, J. M., Huckerby, T. N., Shaw, D. A., Soutar, I., \& Swanson, L. (2003). Studies of the "Smart" Thermoresponsive Behavior of Copolymers of NIsopropylacrylamide and N,N-Dimethylacrylamide in Dilute Aqueous Solution. 7765-7770, 36(20), 7765-7770.

Barmar, M., Kaffashi, B., \& Barikani, M. (2010). Investigating the Uni-HEUR Thickener Performance considering Hydrophilic Segment Lenght. Colloids and Surfaces A: Physicochemical and Engineering Aspects, 364, 105-108.

Beckham, J. (2018, July 03). Offshore. Retrieved from A PennWell Corporation Website: https://www.offshore-mag.com/articles/print/volume-78/issue-2/productionoperations/chevron-starts-polymer-injection-at-captain-in-north-sea.html

Branham, K. D., Snowden, H. S., \& McCormick, C. L. (1996). Water Soluble Copolymers. 64. Effects of $\mathrm{pH}$ and Composition on Associative Properties of Amphiphilic Acrylamide/Acrylic Acid Terpolymers. Macromolecules, 29, 254-262.

Brassinne, J., Bourgeois, J.-P., Fustin, C.-A., \& Gohy, J.-F. (2014). Thermo-responsive Properties of Metallo-Supramolecular Block Copolymer Micellar Hydrogels. Soft Matter, 10, 3086-3092.

Candau, F., \& Selb, J. (1999). Hydrophobically-Modified Polyacrylamides Prepared by Micellar Polymerization. Advances in Colloid and Interface Science, 79(2-3), 149172.

Candau, F., Biggs, S., Hill, A., \& Selb, J. (1994). Synthesis, Structure and Properties of Hydrophobically Associating Polymers. Progress in Organic Coatings, 24(1-4), 1119.

Çavuş, S. (2010). Poly(methacrylamide-co-2-acrylamido-2-methyl-1-propanesulfonic acid) Hydrogels: Investigation of $\mathrm{pH}$ - and Temperature-Dependent Swelling Characteristics and their Characterization. Journal of Polymer Science Part B: Polymer Physics, 48(23), 2497-2508.

Chen, H., Ye, Z., Han, L., \& Luo, P. (2012). Studies on the Self-assembly Behavior of the Hydrophobically Associating Polyacrylamide. Journal of Applied Polymer Science, 123(4), 2397-2405. 
Chen, T., Song, Z., Fan, Y., Hu, C., Qiu, L., \& Tang, J. (1998). A Pilot Test of Polymer Flooding in an Elevated Temperature Reservior. SPE Reservior Evaluation and Engineering , 1(1), 24-29.

Chen, Z. (2016). Polyacrylamide and its Derivatives for Oil Recovery. Missouri University of Science and Technology, Department of Chemistry. Missouri: Missouri University of Science and Technology.

Chiappa, L., Mennella, A., Lockhart, T. P., \& Burrafato, G. (1999). Polymer Adsorption at the Brine/Rock Interface: The Role of Electrostatic Interactions and Wettability. Journal of Petroleum Science and Engineering, 24, 113-122.

Choi, B., Jeong, M. S., \& Lee, K. S. (2014). Temperature-Dependent Viscosity Model of HPAM Polymer through High-Temperature Reservoirs. Polymer Degradation and Stability, 110, 225-231.

Choi, J., Ka, D., Chung, T., Jung, J., Koo, G., Uhm, T., . . Jung, H. (2015). Evaluation of Highly Stable Ultrahigh-Molecular-Weight Partially Hydrolyzed Polyacrylamide for Enhanced Oil Recovery. Molecular Research, 23(6), 518-524.

Cilurzo, F., Selmin, F., Gennari, C., Montanari, L., \& Minghetti, P. (2014). Application of Methyl Methacrylate Copolymers to the Development of Transdermal or LocoRegional Drug Delivery Systems. Expert Opinion on Drug Delivery , 11(7), 10331045.

Clarke, A., Howe, M. A., Mitchell, J., Staniland, J., Hawkes, L., \& Leeper, K. (2015). Mechanism of Anomalously Increased Oil Displacement with Viscoelastic Polymer Solutions. Soft Matter, 11, 3536-3541.

Cui, Q., Zhang, J., Xue, T., \& Zhang, J. (2016). Study on Synthesis and Application Performance of Hydrophobic Associated Polymer Drag Reducing Agent. Journal of Residuals Science \& Technology, 13(6), 1-10.

Dai, C., Xu, Z., Wu, Y., Zou, C., Wu, X., Wang, T., . . Z Zhao, M. (2017). Design and Study of a Novel Thermal-Resistant and Shear-Stable Amphoteric Polyacrylamide in HighSalinity Solution. Polymers, 9(7), 1-12.

Dai, Y., Wu, F., Li, M., \& Wang, E. (2008). Properties and influence of hydrophobically associating polyacrylamide modified with 2-phenoxylethylacrylate. Frontiers of Material Science in China, 2(1), 113-118.

Das, B. M., Gogoi, S. B., \& Mech, D. (2017). Micellar-polymer for enhanced oil recovery for Upper Assam Basin. Resource Efficient Technologies, 3, 82-87.

Deen, G. R. (2012). Solution Properties of Water-Soluble "Smart” Poly(N-acryloyl-N'-ethyl piperazine-co-methyl methacrylate). Polymers, 4, 32-45.

Delamaide, E., Zaitoun , A., \& Renard , G. (2013). Pelican Lake Field: First Successful Application of Polymer Flooding in a Heavy Oil Reservoir . SPE Enhanced Oil Recovery Conference (pp. 1-22). Kuala Lumpur: Society of Petroleum Engineers. 
Deng, Q., Li, H., Li, Y., Cao, X., Yang, Y., \& Song, X. (2014). Rheological Properties and Salt Resistance of a Hydrophobically Associating Polyacrylamide. Australian Journal of Chemistry, 67(10), 1396-1402.

Deng, S. B., Bai, R. B., Chen, J. P., Yu, G., Jiang, Z., \& Zhou, F. (2002). Effects of alkaline/surfactant/polymer on stability of oil droplets in produced water from ASP flooding. Colloids and Surfaces A: Physicochemical and Engineering Aspects, 211(23), 275-284.

Duhamel, J. (2012). Internal Dynamics of Dendritic Molecules Probed by Pyrene Excimer Formation. Polymers, 4(1), 211-239.

Dupuis, G., Rousseau, D., Tabary, R., \& Grassi, B. (2010). How to Get the Best Out of Hydrophobically Associating Polymersfor IOR? New Experimental Insights. SPE Improved Oil Recovery Symposium. Oklahoma, USA.

Dupuis, G., Rousseau, D., Tabary, r., \& Grassi, B. (2011). Flow of Hydrophobically Modified Water-Soluble Polymer Solutons in Porous Media: New Experimental Insights in the Diluted Regime. SPE Journal, 16(1), 43-54.

El-Hoshoudy, A. N., Desouky, S. E., Al-Sabagh, A. M., Betiha, M. A., El-Kady, M. Y., \& Mahmoud, S. (2015). Synthesis and Characterization of Polyacrylamide Crosslinked Copolymer for Enhanced Oil Recovery and Wettability Alteration. International Journal of Oil, Gas and Coal Engineering, 3(4), 43-55.

El-Hoshoudy, A. N., Desouky, S. E., Al-Sabagh, A. M., Betiha, M. A., El-Kady, M. Y., \& Mahmoud, S. (2017). Evaluation of Solution and Rheological Properties for Hydrophobically Associated Polyacrylamide Copolymer as a Promised Enhanced Oil Recovery Candidate. Egyptian Journal of Petroleum, 26, 779-785.

Fang, C., Jing, Y., Zong, Y., \& Lin, Z. (2016). Effect of N,N-dimethylacrylamide (DMA) on the Comprehensive Properties of Acrylic Latex Pressure Sensitive Adhesives. International Journal of Adhesion and Adhesives, 71, 105-111.

Feng, H., Lu, X., Wang, W., Kang, N., \& Mays, J. W. (2017). Block Copolymers: Synthesis, Sel-Assembly and Applications. Polymers, 9, 1-31.

Feng, Y. J., Billon, L., Grassl, B., Bastiat, G., Borisov, O., \& Francois, J. (2005). Hydrophobically Associating Polyacrylamides and their Partially Hydrolyzed Derivaties Prepared by Post-Modification. 2. Properties of Non-Hydrolyzed Polymers in Pure Water and Brine. Polymer, 46(22), 9283-9295.

Fernyhough, C., Ryan, A. J., \& Battaglia, G. (2009). pH Controlled Assembly of a Polybutadiene-Poly(methacrylic acid) Copolymer in Water: Packing Considerations and Kinetic Limitations. Soft Matter, 5(8), 1674-1682 .

Gao, C. H. (2011). Scientific Research and Field Applications of Polymer Flooding in Heavy Oil Recovery. Journal of Petroleum Exploration and Production Technology, 1, 6570 . 
Gao, C. H. (2014). Experiences of Polymer Flooding Projects at Shengli Oilfield. SPE EOR Conference at Oil and Gas West Asia. Muscat: Society of Petroleum Engineers.

Giz, A., Cüatalgil-Giz, H., Alb, A., Brousseau, J., \& Reed, W. F. (2001). Kinetics and Mechanisms of Acrylamide Polymerization from Absolute, Online Monitoring of Polymerization Reaction. Macromolecules, 34, 1180-1191.

Gong, H. J., Zhang, H., Xu, L., Li, K. N., Yu, L., San, Q., . . . Dong, M. (2017). The Synergistic Effect of Branched Preformed Particle Gel and Hydrolyzed Polyacrylamide on Further Enhanced Oil Recovery after Polymer Flooding. Energy and Fuels, 31, 7904-7910.

Gong, H., Xu, G., Zhu, Y., Wang, Y., Wu, D., Nui, M., .. . Wang, H. (2008). Influencing Factors on the Properties of Complex Systems Consisting of Hydrolyzed Polyacrylamide/Triton X-100/Cetyl Trimethylammonium Bromide: Viscosity and Dynamic Interfacial Tension Studies. Energy and Fuels, 23(1), 300-305.

Gong, L. X., \& Zhang, X. F. (2009). A New Approach to the Synthesis of Hydrophobically Associating Polyacrylamide via the Inverse Miniemulsion Polymerization in the Presence of Template. Express Polymer Letters, 3(12), 778-787.

Gou, S., Luo, S., Liu, T., Zhao, P., He, Y., Pan, Q., \& Guo, Q. (2015). A Novel WaterSoluble Hydrophobically Associating Polyacrylamide Based on Oleic Imidazoline and Sulfonate for Enhanced Oil Recovery. New Journal of Chemistry, 39, 7805-7815.

Guo, Y. J., Liu, J.-X., Zhang, X., Feng, R., Li, H., Zhang, J., . . Luo, P. (2012). Solution Property Investigation of Combination Flooding Systems Consisting of Gemini-Nonionic Mixed Surfactant and Hydrophobically Associating Polyacrylamide for Enhanced Oil Recovery. Energy and Fuels, 26(4), 2116-2123.

Guo, Y., Zhang, J., Zhang, X., Hu, J., Wang, W., \& Liang, Y. (2018). Investigation and Application of an Associative Polymer-Surfactant Binary System for a Successful Flooding Pilot in a High Temperature, High Salinity Ordinary Heavy Oil Reservior. SPE EOR Conference at Oil and Gas West Asia. Muscat, Oman.

Han, F. Q., Shao, B., Wang, Q. W., Guo, C. G., \& Liu, Y. X. (2010). Synthesis and Characterization of Carboxymethylcellulose and Methyl Methacrylate Graft Copolymers. Pigment \& Resin Technology, 39(3), 156-162.

Han, F., Xiong, D., Wang, Q., Shao, B., \& Chen, M. (2013). Thermal Properties of Carboxymethylcellulose and Methyl Methacrylate Graft Copolymers. Journal of Macromolecular Science Part B: Physics, 52(9), 1242-1249.

Han, M., Xiang, W., Zhang, J., Jiang, W., \& Sun, F. (2006). Application of EOR Technology by Means of Polymer Flooding in Bohai Oil Fields. SPE International Oil and Gas Conference and Exhibition. Beijing, China.

Hood, M. A., Mari, M., \& Muñoz-Espí, R. (2014). Synthetic Strategies in the Preparation of Polymer/Inorganic Hybrid Nanoparticles. Materials, 7, 4057-4087. 
Hourdet, D., Gadgil, J., Podhajecka, K., Badiger, M., Brulet, A., \& Wadgaonkar, P. (2005). Thermoreversible Behavior of Associating Polymer Solutions: Thermothinning versus Thermothickening. Macromolecules, 38, 8512-8521.

Huaiping, Z., Xu, K., Ai, H., Chen, D., Xv, L., \& Chen, M. (2008). Synthesis, Characterization and Solution Properties of Hydrophobically Modified Polyelectrolyte Poly(AA-co-TMSPMA). Journal of Solution Chemistry, 37, 11371148.

Ihara, T., Nishioka, T., Kamitani, H., \& Kitsuki, T. (2004). Solution Properties of Novel Polysaccharide Derivative. Chemical Letters, 33, 1094-1095.

Jincheng, M., Tan, H., Yang, B., Zhang, W., Yang, X., Zhang, Y., \& Zhang, H. (2018). Novel Hydrophobic Associating Polymer with Good Salt Tolerance. Polymers, 10(8), $1-19$.

Jordan, J. H., \& Gibb, B. C. (2015). Molecular Containers Assembled through the Hydrophobic Effect. Chemical Society Reviews, 44(2), 547-585 .

Kamal, M. S., Sultan, A. S., Al-Mubaiyedh, U. A., \& Hussein, I. A. (2015). Review on Polymer Flooding: Rheology, Adsorption, Stability, and Field Applications of Various Polymer Systems. Polymer Reviews, 1-40.

Kang, K. W., Hwang, C. W., \& Hwang, T. S. (2015). Synthesis and Properties of Sodium Vinylbenzene Sulfonate-Grafted Poly(vinylidene fluoride) Cation Exchange Membranes for Membrane Capacitive Deionization Process. Macromolecular Research, 23(12), 1126-1133.

Kang, P. S., Lim, J. S., \& Huh, C. (2016). Screening Criteria and Considerations of Offshore Enhanced Oil Recovery. Energies, 9(44), 1-18.

Kastner, U., Hoffmann, H., Donges, R., \& Ehrler, R. (1996). Interactions between Modified Hydroxyethyl Cellulose (HEC) and Surfactants. Colloids and Surfaces A: Physicochemical and Engineering Aspects, 112, 209-225.

Kawakami, K., Ihara, T., Nishioka, T., Kitsuki, T., \& Suzuki, Y. (2006). Salt Tolerance of an Aqueous Solution of a Novel Amphiphilic Polysaccharide Derivative. Langmuir, 22, 3337-3343.

Khromiak, U., Levytskyi, V., Stepova, K., \& Tarnawsky, A. (2018). Synthesis and Properties of Adhesive Polymer-Methylmethacrylate Materials. International Journal of Polymer Science, 2018, 1-9.

Kjoniksen, A. L., Beheshti, N., Kotlar, H. K., Zhu, K. Z., \& Nystrom, B. (2008). Modified Polysaccharides for use in Enhanced Oil Recovery. European Polymer Journal, 44, 959-967.

Kornberger, M., Gumpenberger, T., Deckers, M., Zechner, M., \& Clemens, T. (2013). Polymer Solution Injection-Near Wellbore Dynamics and Displacement Efficiency: 
Pilot Test Results, Matzen Field, Austria. EAGE Annual Conference \& Exhibition incorporating SPE Europec. London: Society of Petroleum Engineers.

Kundakci, S., Karadağ, E., \& Üzüm , O. B. (2011). Investigation of Swelling/Sorption Characteristics of Highly Swollen AAm/AMPS Hydrogels and Semi IPNs with PEG as Biopotential Sorbent . Journal of Encapsulation and Adsorption Sciences, 1, 7-22.

Lai, N., Dong, W., Ye, Z., Dong, J., Qin, X., Chen, W., \& Chen, K. (2013). A Water Soluble Acrylamide Hydrophobically Associating Polymer: Synthesis, Characterization and Properties as EOR Chemical. Journal of Applied Polymer Science, 129(4), 18881896.

Lee, R.-S., Wang, S. W., Li, Y. C., \& Fang, J. Y. (2015). Synthesis and Characterization of Thermo-responsive and Photo-cleavable block Copolymers as Nanocarriers. RSC Advances, 5, 497-512.

Levitt, D. B., \& Pope, G. A. (2008). Selection and Screening of Polymers for Enhanced Oil Recovery. SPE/DOE Improved Oil Recovery Symposium (pp. 1-18). Oklahoma: Society of Petroleum Engineers.

Li, Q., Pu, W., Wei, B., Jin, F., \& Li, K. (2016). Static Adsorption and Dynamic Retention of an Anti-Salinity Polymer in Low Permeability Sandstone Core. Journal of Applied Polymer Science, 134(8), 44487-44494.

Li, X., Shu, Z., Luo, P., \& Ye, Z. (2018). Associating Polymer Networks Based on Cyclodextrin Inclusion Compounds for Heavy Oil Recovery. Journal of Chemistry, 2018, 1-9.

Li, X., Xu, Z., Yin, H., Feng, Y., \& Quan, H. (2017). Comparative Studies on Enhanced Oil Recovery: Thermoviscosifying Polymer Versus Polyacrylamide. Energy and Fuels, $31,2479-2487$.

Liao, G. Z., Wang, Q., Wang, H. Z., Liu, W. D., \& Wang, Z. (2017). Chemical Flooding Development Status and Prospect. Acta Petrolei Sinica, 38(2), 196-207.

Li-Bin, D., Dong-Qing, Z., Shou-Ping, L., \& Yun-Xiang, Z. (2010). Effects of Ethylene Oxide Spacer Length on Solution Properties of Water-Soluble FluorocarbonContaining Hydrophobically Associating Poly (Acrylic Acid-co-Rf-PEG Macromonomer). Chinese Journal of Chemistry, 21(6), 698-705.

Liu, B., Sun, X. S., Wang, K., Xu, H., Liu, Q., Liu, X., \& Song, S. (2007). Flooded by High Concentration Polymer Doubled Oil Recovery of Common Polymer on Field Test with 20\% Closed to the Result of Lab Testing in Daqing. International Oil Conference and Exhibition. Mexico City: Society of Petroleum Engineers.

Liu, X. J., Jiang, W. C., Gou, S. H., Ye, Z. B., \& Xie, X. D. (2012). Synthesis and Evaluation of Water Soluble Acrylamide Binary Sulfonates Copolymer on MMT Crystalline Interspace and EOR. Journal of Polymer Science, 125(2), 1252-1260. 
Liu, X., Jiang, W., Gou, S., Ye, Z., Feng, M., Lai, N., \& Liang, L. (2013). Synthesis and Evaluation of Novel Water Soluble Copolymers based on Acrylamide and Modular Beta-cyclodextrin. Carbohydrate Polymers, 96(1), 47-56.

Lu, H., Huang, Z., \& Feng, Y. (2010). Solution Association Characterization of Hydrophobically Associating Polyacrylamide Obtained from Produced Fluids. Journal of Macromolecular Science, Part A: Pure and Applied Chemistry, 47, 423428.

Maia, A. M., Costa, M., Borsali, R., \& Garcia, R. B. (2005). Rheological Behavior and Scattering Studies of Acrylamide Based Copolymer Solutions. Macromolecular Symposia, 229(1), 217-227.

Mei, Y., Bai, Y., \& Wang, L. (2016). Effect of pH on Binding of Pyrene to Hydrophobic Fractions of Dissolved Organic Matter (DOM) Isolated from Lake Water. Acta Geotechnica, 35(3), 288-293.

Meiqin, L., Chunling, Z., Hua, Z., Mingyuan, L., Hongbo, F., \& Jixiang, G. (2008). Influence of Polymers on the Stability of Gudao Crude Oil Emulsions. Petroleum Science, 5, 159-162.

Meyers, J. J., Pitts, M. J., \& Wyatt , K. (1992). Alkaline-Surfactant-Polymer Flood of the West Kiehl, Minnelusa Unit. SPE/DOE Enhanced Oil Recovery Symposium. Oklahoma: Society of Petroleum Engineers.

Mogollon, J. L., \& Lokhandwala, T. (2013). Rejuvenating Viscous Oil Reservoirs by Polymer Injection: Lessons Learned in the Field. SPE Enhanced Oil Recovery Conference. Kuala Lumpur: Society of Petroleum Engineers.

Mori, H., Kudo, E., Saito, Y., Onuma, A., \& Morishima, M. (2010). RAFT Polymerization of Vinyl Sulfonate Esters for the Controlled Synthesis of Poly(lithium vinyl sulfonate) and Sulfonated Block Copolymers. Macromolecules, 43(17), 7021-7032.

Mori, H., Saito, Y., Takahashi, E., Nakabayashi, K., Onuma, A., \& Morishima, M. (2012). Controlled Synthesis of Sulfonated Block Copolymers having Thermoresponsive Property by RAFT Polymerization of Vinyl Sulfonate Esters. Polymer, 53(18), 38613877.

Nesrinne, S., \& Djamel, A. (2017). Synthesis, Characterization and Rheological Behavior of pH Sensitive Poly(acrylamide-co-acrylic acid) Hydrogels. Arabian Journl of Chemistry, 10(4), 539-547.

Niskanen, J., \& Tenhu, H. (2017). How to Manipulate the Upper Critical Solution Temperature (UCST)? Polymer Chemistry, 8, 220-232.

Oh, S. Y., Kim, H. J., \& Bae, Y. C. (2013). Molecular Thermodynamic Analysis for Phase Transitions of Linear and Cross-linked Poly(N-isopropylacrylamide) in Water/2propanol Mixtures. Polymer, 54, 6776-6784. 
Oruwori, A. E., \& Ikiensikimama , S. S. (2010). Determination of Water Salinities in Hydrocarbon Bearing Reservoirs of Some Niger Delta Fields - Nigeria. Nigeria Annual International Conference and Exhibition (pp. 1-10). Calabar: Society of Petroleum Engineers.

Page, M., Lecourtier, J., Noik, C., \& Foissy, A. (1993). Adsorption of Polyacrylamides and Polysaccharides on Siliceous Materials and Kaolinite: Influence of Temperature. Journal of Colloid and Interface Science, 161(2), 450-454.

Pancharoen, M. (2009). Physical Properties of Associative Polymer Solutions. Stanford University, Department of Energy Resources Engineering. Stanford: Stanford University.

Pancharoen, M., Thiele, M. R., \& Kovscek, A. R. (2010). Inaccessible Pore Volume of Associative Polymer Floods. SPE Improved Oil Recovery Symposium. Oklahoma: Society of Petroleum Engineers.

Pandey, S., Redden, R. A., Hendricks, A. E., Flectcher, K. A., \& Palmer, C. P. (2003). Characterization of the Solvation Environment Provided by Dilute Aqueous Solutions of Novel Siloxane Polysoaps using the Fluorescence Probe Pyrene. Journal Coolid Interface Science, 262(2), 579-587.

Panthi, K., Mohanty, K., \& Sharma, H. (2013). ASP Flood of a Viscous Oil in a Carbonate Rock. SPE Annual Technical Conference and Exhibition. New Orleans: Society of Petroleum Engineers.

Patokina, O. Y. (2015). Polymer Flooding by Hydrophobically Associating Polyacrylamide (Technology of Preparation. The Study of the Process Stability and Degradation). SPE Russian Petroleum TechnologyConference. Moscow, Russia.

Pavlov, G. M., Dommes, O. A., Gosteva, A. A., Okatova, O. V., Gavrilova, I. I., \& Panarin, E. F. (2018). Sizes of Macromolecules of Copolymers of N-Methyl-NVinylacetamide and N-Methyl-N-Vinylamine Hydrochloride with Low Charge Linear Density. Polymer Science, Series A, 60(2), 172-178.

Pitts, M. J., Wyatt, K., \& Surkalo, H. (2004). Alkaline-Polymer Flooding of the David Pool, Lloydminster Alberta. SPE/DOE Symposium on Improved Oil Recovery. Oklahoma: Society of Petroleum Engineers.

Pitts, M., Dowling, P., Wyatt, K., Surkalo, H., \& Adams , K. C. (2006). Alkaline-SurfactantPolymer Flood of the Tanner Field. SPE/DOE Symposium on Improved Oil Recovery. Oklahoma: Society of Petroleum Engineers.

Pratap, M., \& Gauma, M. S. (2004). Field Implementation of Alkaline-Surfactant-Polymer (ASP) Flooding : A maiden effort in India. SPE Asia Pacific Oil and Gas Conference and Exhibition. Perth: Society of Petroleum Engineers. 
Prazeres, T. J., Beingessner, R., \& Duhamel, J. (2001). Characterization of the Association Level of Pyrene-Labeled HASEs by Fluorescence. Macromolecules, 34(22), 78767884.

Principi, T., Ester-Goh, C. C., Liu, R. C., \& Winnik, F. M. (2000). Solution Properties of Hydrophobically Modified Copolymers of N-Isopropylacrylamide and N-Glycine Acrylamide: A Study by Microcalorimetry and Fluorescence Spectroscopy. Macromolecules, 33(8), 2958-2966.

Pu, H., \& Xu, Q. (2009). An Update and Perspective on Field-scale Chemical Floods in Daqing Oilfield. SPE Middle East Oil and Gas Show and Conference. Manama: Society of Petroleum Engineers.

Qavi, S., Pourmahdian, S., \& Eslami, H. (2014). Acrylamide Hydrogels Preparation via Free Radical Crosslinking Copolymerization: Kinetic Study and Morphological Investigation. Journal of Macromolecular Science, Part A: Pure and Applied Chemistry, 51(10), 842-848.

Quan, H., Li, Z., \& Huang, Z. (2016). Self-Assembly Properties of a Temperature and Salt Tolerant Amphoteric Hydrophobically Associating Polyacrylamide. RSC Advances, 6, 49281-49288.

Quan, H., Lu, Q., Chen, Z., Huang, Z., \& Jiang, Q. (2019). Adsorption-Desorption Behavior of the Hydrophobically Associating Copolymer AM/APEG/C-18/SSS. RSC Advances, 9, 12300-12309.

Raffa, P., Broekhuis, A. A., \& Picchioni, F. (2016). Polymeric Surfactants for Enhanced Oil Recovery: A Review. Journal of Petroleum Science and Engineering, 145, 723-733.

Rashidi, M., Blokhus, A. M., \& Skauge, A. (2010). Viscosity Study of Salt Tolerant Polymers. Journal of Applied Polymer Science, 117, 1551-1557 .

Rashidi, M., Sandvik, S., Blokhus, A., \& Skauge, A. (2009). Static and Dynamic Adsorption of Salt Tolerant Polymers. 15th European Symposium on Improved Oil Recovery. Paris: Society of Petroleum Engineers.

Reichenbach-Klinke, R., Stavland, A., Strand, D., Langlotz, B., \& Brodt, G. (2016). Can Associative Polymers Reduce the Residual OIl Saturation. SPE EOR Conference at Oil and Gas West Asia. Muscat: Society of Petroleum Engineers.

Rintoul, I. (2017). Kinetic Control of Aqueous Polymerization Using Radicals Generated in Different Spin States. Processes, 5(2), 1-12.

Sabhapondit, A., Borthakur, A., \& Haque, I. (2003). Water Soluble Acrylamidomethyl Propane Sulfonate (AMPS) Copolymer as an Enhanced Oil Recovery Chemical . Energy and Fuels, 17(3), 683-688.

Saeed, A., Mahmood, S. M., Tan, I. M., Ghaedi, H., \& Ling, O. L. (2017). Assessment of Polyacrylamide Based Co-Polymers Enhanced by Functional Group Modifications with Regards to Salinity and Hardness. Polymers, 9, 1-16. 
Santis, S. D., Mesa, C., \& Masci, G. (2017). On the Upper Critical Solution Temperature of PNIPAAM in an Ionic Liquid: Effect of Molecular Weight, Tacticity and Water. Polymer, 120, 52-58.

Sarsenbekuly, B., Kang, W., Fan, H., Yang, H., Dai, C., Zhao, B., \& Aidarova, S. B. (2017). Study of Salt Tolerance and Temperature Resistance of a Hydrophobically Modified Polyacrylamide based Novel Functional Polymer for EOR. Colloids and Surfaces A: Physicochemical and Engineering Aspects, 514, 91-97.

Seright, R. S., Fan, T., Wavrik, K., Wan, H., Galliard, N., \& Favero, C. (2011). Rheology of a New Sulfonic Associative Polymer in Porous Media. SPE Reservior Evaluation and Evaluation, 14(6), 726-734.

Sharafi, M. S., Jamialahmadi, M., \& Hoseinpour, S.-A. (2018). Modeling of Viscoelastic Polymer Flooding in Core-Scale for Prediction of OIl Recovery using Numerical Approach. Journal of Molecular Liquids, 250, 295-306.

Shatat, R. S., \& Niazi, S. K. (2018). Using Free Radical Polymerization and Mannich Reaction, Synthesis and Characterization of Cationic Polyacrylamides having Similar Molecular Weight but Different Charge Densities. European Journal of Chemistry, 9(2), 79-83.

Shemper, B. S., Acar, A. E., \& Mathias, L. J. (2002). Synthesis of Linear and Starlike Polymers from Poly(propylene glycol) Methacrylate using Controlled Radical Polymerization. Journal of Polymer Science Part A: Polymer Chemistry, 40(3), 334343.

Sheng, J. J. (2011). Modern Chemical Enhanced Oil Recovery, Gulf Professional Publishing.

Silva, I. P., Aguiar, A. A., Rezende, V. P., Monsores, A. L., \& Lucas, E. F. (2018). A Polymer Flooding Mechanism for Mature Oil Fields: Laboratory Measurements and Field Results Interpretation. Journal of Petroleum Science and Engineering, 161, 468475.

Siu, H., \& Duhamel, J. (2008). Molar Absorption Coefficient of Pyrene Aggregates in Water. Journal of Physical Chemistry B, 112(48), 15301-15312.

Skauge, A., Zamani, N., Jacobsen, J. G., Shiran, B. S., Al-Shakry, B., \& Skauge, T. (2018). Polymer Flow in Porous Media: Relevance to Enhanced Oil Recovery. Cooloids and Interfaces, 2(3), 1-27.

Smith, G. L., \& McCormick, C. L. (2001). Water Soluble Polymers. 80. Rheological and Photophysical Studies of pH Responsive Terpolymers Containing Hydrophobic TwinTailed Acrylamide Monomers. Macromolecules, 34, 5579-5586.

Sun, J., Du, W., Pu, X., Zou, Z. Z., \& Zhu, B. B. (2015). Synthesis and Evaluation of a Novel Hydrophobically Associating Polymer Based on Acrylamide for Enhanced Oil Recovery. Chemical Papers, 69(12), 1598-1607. 
Szymański, J. K., Abul-Haija, Y. M., \& Cronin, L. (2018). Exploring Strategies To Bias Sequence in Natural and Synthetic Oligomers and Polymers. Accounts of Chemical Research, 51, 649-658.

Taghizadeh, M. T., \& Foroutan, M. (2004). Water-soluble Copolymers of N-vinylpyrrolidone and Vinyl Acetate: Synthesis, Characterization, and Monomer Reactivity at High Conversions. Journal of Polymer Research, 11(3), 203-209.

Taheri-Shakib, J., Hosseini, S. A., Kazemzadeh, E., Keshavarz, V., Rajabi-Kochi, M., \& Naderi, H. (2019a). Experimental and Mathematical Model Evaluation of Asphaltene Fractionation Based on Adsorption in Porous Media: Dolomite Reservoir Rock. Fuel, $245,570-585$.

Taheri-Shakib, J., Keshavarz, V., Kazemzadeh, E., Hosseini, S. A., Rajabi-Kochi, M., Salimidelshad, Y., Naderi, H., \& Baktiari, H. A. (2019b). Experimental and Mathematical Model Evaluation of Asphaltene Fractionation Based on Adsorption in Porous Media: Part 1. Calcite Reservoir Rock. Journal of Petroleum Science and Engineering, 177, 24-40.

Tam, K. C., Jenkins, R. D., Winnick, M. A., \& Bassett, D. R. (1998). A Structural Model of Hydrophobically Modified Urethane-Ethoxylate (HEUR) Associative Polymers in Shear Flows. Macromolecules, 31, 4149-4159.

Tang, Y., Liu, S. Y., Armes, S. P., \& Billingham, N. C. (2003). Solubilization and Controlled Release of a Hydrophobic Drug Using Novel Micelle-Forming ABC Triblock Copolymers. Biomacromolecules, 4, 1636-1645.

Taylor, K. C., \& Nasr El-Din, H. A. (1998). Water Soluble Hydrophobically Associating Polymers for Improved Oil Recovery: A Literature Review. Journal of Petroleum Science and Engineering, 19, 265-280.

Tiwari, D., Marathe, R., Patel, N., Ramachandran, K., Maurya, C., \& Tewari, P. (2008). Performance Of Polymer Flood In Sanand Field, India - A Case Study. SPE Asia Pacific Oil and Gas Conference and Exhibition. Perth: Society of Petroleum Engineers.

Torrealba, V. A., \& Hoteit, H. (2019). Improved Polymer Flooding Injectivity and Displacement by Considering Compositionally-Tuned Slugs. Journal of Petroleum Science and Engineering, 178, 14-26.

Vargo, J., Turner, J., Bob, V., Pitts, M., Wyatt, K., Surkalo , H., \& Patterson , D. (2000). Alkaline-Surfactant-Polymer Flooding of the Cambridge Minnelusa Field. SPE Reservoir Evaluation \& Engineering, 3(6), 1-7.

Victor, R., Woisel, P., \& Hoogenboom, R. (2016). Supramolecular Control over Thermoresponsive Polymers. Materials Today, 19(1), 44-55.

Volpert., E., Selb, J., \& Candau, F. (1998). Adsorption of Hydrophobically Associating Polyacrylamides on Clay. Langmuir, 14(7), 1870-1879. 
Wang, F., Peng, J., Dong, R., Chang, X., Ren, B., \& Tong, Z. (2016). Highly Efficient Hydrophobically Modified Ethoxylated Urethanes(HEURs) End-Functionalized by Two-Tail Dendritic Hydrophobes:Synthesis, Solution Rheological Behavior and Thickening in Latex. Colloids and Surfaces A: Physicochemical and Engineering Aspects, 502, 114-120.

Wassmuth, F., Green, K., \& Bai, J. (2012). Associative Polymers Outperform Regular Polymers Displacing Heavy Oil in Heterogenous Systems. SPE Heavy Oil Conference . Alberta, Canada.

Wei, Z., Jian, Z., Ming, H., Wentao, X., Guozhi, F., Wei, J., . . . Shouwei, Z. (2007). Application of Hydrophobically Associating Water Soluble Polymer for Polymer Flooding in China Offshore Heavy Oilfield. International Petroleum Technology Conference (pp. 1-5). Dubai: Society of Petroleum Engineers.

Wever, D. A., Picchioni, F., \& Broekhuis, A. A. (2011). Polymers for Enhanced Oil Recovery: A Paradigm for Structure-Property Relationship in Aqueous Solution. Progress in Polymer Science, 36, 1558-1628.

Wever, D. A., Picchioni, F., \& Broekhuis, A. A. (2013). Comblike Polyacrylamides as Flooding Agent in Enhanced Oil Recovery. Industrial and Engineering Chemistry Research, 52, 16352-16363.

Willersinn, J., \& Schmidt, B. V. (2017). Self-Assembly of Double Hydrophilic Poly(2-ethyl2-oxazoline)-b-poly(N-vinylpyrrolidone) Block Copolymers in Aqueous Solution. Polymers, 9(7), 1-15.

Wyatt, N. B., Gunther, C. M., \& Liberatore, M. W. (2011). Increasing Viscosity in Entangled Polyelectrolyte Solutions by the Addition of Salt. Polymer, 52(11), 2437-2444.

Xie, K., Lu, X., Li, Q., Jiang, W., \& Yu, Q. (2016). Analysis of Reservoir Applicability of Hydrophobically Associating Polymer. SPE Journal, 21(1), 1-9.

Xu, B., Yekta, A., Li, L., Masoumi, Z., \& Winnik, M. A. (1996). The Functionality of Associative Polymer Network: The Association Behavior of Hydrophobically Modified Urethane-Ethoxylate (HEUR) Associative Polymers in Aqueous Solution. Colloids and Surfaces A: Physicochemical and Engineering Aspects, 112, 239-250.

Xu, X., Saeedi, A., \& Liu, K. (2016). Laboratory studies on CO2 foam flooding enhanced by a novel amphiphilic ter-polymer. Journal of Petroleum Science and Engineering, 138, 153-159.

Yabin, N., Jian, O., Zhuoyan, Z., Guijiang, W., Guanghua, S., \& Lijun, S. (2001). Research on Hydrophobically Associating Water-Soluble Polymer used for EOR. SPE International Symposium on Oilfield Chemistry (pp. 1-4). Houston: Society of Petroleum Engineers. 
Yamamoto, S., Miyashita, T., \& Mitsuishi, M. (2017). Amphiphilic Acrylamide Block Copolymer: RAFT Block Copolymerization and Monolayer Behaviour. RSC Advances, 7, 44954-44960.

Yan, H., \& Row, K. H. (2006). Characteristic and Synthetic Approach of Molecularly Imprinted Polymer. International Journal of Molecular Sciences, 7, 155-178.

Yang, F., Wang, D., Wang, G., Sui, X., Liu, W., \& Kan, C. (2006). Study on High Concentration Polymer Flooding to Further Enhance Oil Recovery. SPE Annual Technical Conference and Exhibition. Texas: Society of Petroleum Engineers.

Yang, X., Liu, J., Li, P., \& Liu, C. (2015). Self-assembly properties of hydrophobically associating perfluorinated polyacrylamide in dilute and semi-dilute solutions. Journal of Polymer Research, 22(103), 1-7.

Ye, Z., Feng, M., Gou, S., Liu, M., Huang, Z., \& Liu, T. (2013). Hydrophobically Associating Acrylamide-Based Copolymer for Chemically Enhanced Oil Recovery. Journal of Applied Polymer Science, 130(4), 2901-2911.

Yin, H., Wang, D., \& Zhong, H. (2006). Study on Flow Behavior of Viscoelastic Polymer Solution in Micropore with Dead End. SPE Annual Technical Conference and Exhibition (pp. 1-10). Texas: Society of Petroleum Engineers.

Zeng, F., Yang, M., Zhang, J., \& Varshney, S. K. (2002). Synthesis and Characterization of Block Copolymers from 2-vinylnaphthalene by Anionic Polymerization. Journal of Polymer Science Part A: Polymer Chemistry, 40(24), 4387-4397.

Zhang, J., Wang, K., He, F., \& Zhang, F. (1999). Ultimate Evaluation of the Alkali/Polymer Combination Flooding Pilot Test in XingLongTai Oil Field. SPE Asia Pacific Improved Oil Recovery Conference. Kuala Lumpur: Society of Petroleum Engineers.

Zhang, L. J., Yue, X. A., \& Guo, F. (2008). Micro-Mechanisms of Residual Oil Mobilization by Viscoelastic Fluids. Petroleum Science, 5, 56-61.

Zhang, Q., \& Hoogenboom, R. (2015). Polymers with Upper Critical Solution Temperature Behavior in Alcohol/Water Solvent Mixtures. Progress in Polymer Science, 48, 122142.

Zhang, X., Jiang, G., Xuan, Y., Wang, L., \& Huang, X. (2017). Associating Copolymer Acrylamide/Diallyldimethylammonium Chloride/Butyl Acrylate/2-Acrylamido-2methylpropanesulfonic Acid as a Tackifier in Clay-Free and Water-Based Drilling Fluids. Energy and Fuels, 31, 4655-4662.

Zhang, Y., Wang, Y., Xue, F., Wang, Y., Ren, B., Zhang, L., \& Ren, S. (2015). CO2 foam flooding for improved oil recovery: reservior simulation models and influencing factors. Journal of Petroleum Science and Engineering, 133, 838-850.

Zhao, G. Q., \& Chen, S. B. (2007). Nonlinear Rheology of Aqueous Solutions of Hydrophobically Modified Hydroxyethyl Cellulose with Nonionic Surfactant. Journal of Colloid Interface Science, 316, 858-866. 
Zhao, J., Fan, H., You, Q., \& Jia, Y. (2017). Distribution and Presence of Polymers in Porous Media. Energies, 10, 2118-2131.

Zhijian, Q., Yigen, Z., Zhang , X., \& Jialin, D. (1998). A Successful ASP flooding Pilot in Gudong Oil Field. SPE/DOE Improved Oil Recovery Symposium. Oklahoma: Society of Petroleum Engineers.

Zhong, C., Zhang, H., \& Feng, L. (2014). Solution Behavior and Associating Structures of a Salt-tolerant Tetra-polymer containing an Allyl-capped Macromonomer. Journal of Polymer Research, 21, 1-9.

Zhong, H., Zhang, W., Yin, H., \& Liu, H. (2017). Study on the Mechansim of Viscoelastic Polymer Transient Flow in Porous Media. Geofluids, 2017, 1-8.

Zhou, H., Song, G.-Q., Zhang, Y.-X., Chen, J., Jiang, M., Hogen-Esch, T. E., . . Haeussling, L. (2001). Hydrophobically Modified Polyelectrolytes, 4, Synthesis and Solution Properties of Fluorocarbon Containing Poly(acrylic acid). Macromolecular Chemistry and Physics, 202, 3057-3064.

Zhou, S. N., \& Lai, E. P. (2004). N-phenylacrylamide Functional Polymer with High Affinity for Ochratoxin A. Reactive and Functional Polymers, 58(1), 35-42.

Zhou, W., Zhang, J., Feng, G., Jiang, W., Sun, F., Zhou, S., \& Liu, Y. (2008). Key Technologies of Polymer Flooding in Offshore Oilfield of Bohai Bay. SPE Asia Pacific Oil and Gas Conference and Exhibition (pp. 1-5). Perth: Society of Petroleum Engineers.

Zhu, D., Han, Y., Zhang, J., Li, X., \& Feng, Y. (2014). Enhancing Rheological Properties of Hydrophobically Associative Polyacrylamide Aqueous Solutions by Hybriding with Silica Nanoparticles. Journal of Applied Polymer Science, 131(19), 1-8.

Zhu, J., Xiao, W. F., Dong, L. T., \& Teng, F. (2012). Research on the Influence of Stiffness of Copolymer(N-Tert-octylacrylamide/Acrylic acid/Methyl methacrylate/Butylaminoethyl Methacrylate/Hydroxypropyl Methacrylate) by Methyl Methacrylate and N-Tert-Octylacrylamide. Advanced Materials Research, 557-559, 968-972.

Zhuang, D. Q., Da, J. C., Zhang, Y. X., Dieing, R., Ma, L., \& Haeussling, L. (2001). Hydrophobically Modified Polyelectrolytes II: Synthesis and Characterization of Poly(acrylic Acid-co-Alkyl Acrylate). Polymers for Advanced Technologies, 12, 616625.

Zou, C., Zhao, P., Hu, X., Yan, X., Zhang, Y., Wang, X., . . . Luo, P. (2013). BetaCyclodextrin-Functionalized Hydrophobically Associating Acrylamide Copolymer for Enhanced Oil Recovery. Energy and Fuels, 27, 2827-2834. 
Table 1: Example of field applications of different polymer types under different conditions (modified from Kamal et al., 2015)

\begin{tabular}{|c|c|c|c|c|c|}
\hline Country & Field & Polymer Type & $\mathbf{T}\left({ }^{\circ} \mathbf{C}\right)$ & Formation Salinity $(\mathrm{mg} / \mathrm{L})$ & Reference \\
\hline \multirow{7}{*}{ China } & Daqing & HPAM & 45.0 & 9000 & (Pu and $\mathrm{Xu}, 2009)$ \\
\hline & Gudong & HPAM & 68.0 & 3022 & (Zhijian et al., 1998) \\
\hline & Bohai Bay & HPAM & 65.0 & 6070 & $\begin{array}{c}\text { (Mogollon and Lokhandwala } \\
\text { 2013) }\end{array}$ \\
\hline & Xing Long Tai & HPAM & 56.6 & 3112 & (Zhang et al., 1999) \\
\hline & Bohai oil field & HAPAM & 65.0 & 32423 & (Han et al., 2006) \\
\hline & Henan oil field & HPAM & 75.0 & 5060 & (Chen et al., 1998) \\
\hline & Shengli & HPAM & 70.0 & 10000 & $(\mathrm{Gao}, 2014)$ \\
\hline \multirow{4}{*}{ USA } & Cambridge Minnelusa & PAM & 55.6 & Not specified & (Vargo et al., 2000) \\
\hline & Tambaredjo & HPAM & 36.0 & Not Specified & $\begin{array}{c}\text { (Mogollon and Lokhandwala } \\
\text { 2013) }\end{array}$ \\
\hline & Tanner & PAM & 80.0 & $66800(\mathrm{P})^{\mathrm{a}}$ & (Pitts et al., 2006) \\
\hline & West Khiel & HPAM & 57.0 & $46,480(\mathrm{P})^{\mathrm{a}}$ & (Meyers et al., 1992) \\
\hline \multirow[t]{2}{*}{ Canada } & Pelican & HPAM & 23.0 & 6800 & $\begin{array}{c}\text { (Mogollon and Lokhandwala } \\
\text { 2013) }\end{array}$ \\
\hline & David pool & PAM & 31.0 & $6660(\mathrm{I})^{\mathrm{b}}$ & (Pitts et al., 2004) \\
\hline \multirow{2}{*}{ Germany } & Eddesse-Nord & Xanthan Gum & 22.0 & 120,000 & (Abbas et al., 2013) \\
\hline & Vorhop-Knesebeck & Xanthan Gum & 56.0 & 210,000 & (Abbas et al., 2013) \\
\hline Austria & Matzen & HPAM & 50.0 & 20,000 & (Kornberger et al., 2013) \\
\hline \multirow{2}{*}{ India } & Viraj & HPAM & 81.0 & 13,250 & (Pratap and Gauma, 2004) \\
\hline & Sanand & PAM & 85.0 & Not specified & (Tiwari et al., 2008) \\
\hline Russia & Romashkino (Tatarstan) & HEC & 36.0 & 250,000 & (Abbas et al., 2013) \\
\hline
\end{tabular}

${ }^{a}$ Produced water salinity. ${ }^{b}$ Injection water salinity. 
Table 2: Core flooding studies on some selected polymers (modified from Kamal et al., 2015)

\begin{tabular}{|c|c|c|c|c|c|c|}
\hline Polymer Type & $\begin{array}{c}\text { Polymer Concentration } \\
\text { (ppm) }\end{array}$ & $\mathbf{T}\left({ }^{\circ} \mathbf{C}\right)$ & $\begin{array}{l}\text { Salinity } \\
(\mathrm{mg} / \mathrm{L})\end{array}$ & Core Type & $\operatorname{Recovery}^{\text {a }}(\%)$ & Reference \\
\hline Xanthan Gum & 500 & 50 & - & Sandstone & $66 \mathrm{~T}$ & (Austad et al., 1997) \\
\hline HAPAM & 1000 & 50 & - & Sandstone & $53.6 \mathrm{~T}$ & (Austad et al., 1997) \\
\hline HAPAM & 5000 & 60 & 5000 & Sandstone & 8.5 & (Liu et al., 2012) \\
\hline HAPAM & 2000 & 60 & 5000 & Sandstone & 11 & (Sabhapondit et al., 2003) \\
\hline HPAM & 2000 & 70 & 10000 & Sandstone & 34 & (Gong et al., 2008) \\
\hline HAPAM & 7000 & 60 & 5000 & Sandstone & 10.6 & (Ye et al., 2013) \\
\hline HPAM & 1100 & 75 & 12000 & Sandstone & 9.8 & (Chen et al., 1998) \\
\hline HPAM & 2500 & 45 & $508-6778$ & Sandstone & 16.7 & $\begin{array}{c}\text { (Yang et al., 2006; Liu et } \\
\text { al., 2007) }\end{array}$ \\
\hline HPAM & 4500 & 38 & 30700 & Carbonate & 45 & (Panthi et al., 2013) \\
\hline HAPAM & 2000 & 60 & - & Not specified ${ }^{b}$ & 12 & (Liu et al., 2013) \\
\hline HAPAM & 2000 & 60 & - & Not specified ${ }^{b}$ & 18 & (Liu et al., 2013) \\
\hline HAPAM & 2000 & 65 & 5000 & Sandstone & 5.7 & (Lai et al., 2013) \\
\hline
\end{tabular}

${ }^{a}$ Recovery reported with $T$ as total recovery while remaining value are additional recovery due to $P F .{ }^{b}$ Not indicated in the corresponding article. 
Table 3: Example of monomers employed in polymer modification.

\begin{tabular}{|c|c|}
\hline Monomer & Reference \\
\hline$N, N$-dimethyl Acrylamide & (Algi and Okay, 2014; Fang et al., 2016) \\
\hline 2-vinylnaphtahlene & (Zeng et al., 2002) \\
\hline Methacrylic Acid & (Fernyhough et al., 2009; Bang et al., 2017) \\
\hline$N$-vinylpyrrolidinone & (Taghizadeh and Foroutan, 2004; Willersinn and Schmidt, 2017) \\
\hline 4-vinylbenzenesulfonate & (Kang et al., 2015) \\
\hline 2-Acrylamido-2-methyl-1-propanesulfonic acid & (Çavuş, 2010; Kundakci et al., 2011) \\
\hline Methyl methacrylate & (Cilurzo et al., 2014; Khromiak et al., 2018) \\
\hline Poly(propylene glycol) methacrylate & (Shemper et al., 2002) \\
\hline Sodium vinylsulfonate & (Mori et al., 2010; Mori et al., 2012) \\
\hline Carboxymethyl cellulose & (Han et al., 2010; Han et al., 2013) \\
\hline$N$-phenylacrylamide & (Zhou and Lai, 2004) \\
\hline$N$-tert-Octylacrylamide & (Zhu et al., 2012) \\
\hline$N$-dodecylacrylamide & (Wan et al., 2014) \\
\hline$N$-methyl- $N$-vinyl acetamide & (Pavlov et al., 2018) \\
\hline$N$-(n-octadecyl)acrylamide & (Principi et al., 2000) \\
\hline
\end{tabular}


Table 4: Critical Aggregation Concentration (ppm) data as a function of salinity for the studied sulfonated polymers (AN105 - AN132) at 20 ${ }^{\circ} \mathrm{C}$ (Rashidi et al., 2010)

\begin{tabular}{ccc}
\hline & & Solvents \\
\cline { 2 - 3 } Polymers & CAC (at 0.1 wt.\% NaCl) & CAC (at 10 wt.\% NaCl) \\
\hline AN105 & 264 & 625 \\
\hline AN113 & 250 & 556 \\
\hline AN125 & 244 & 527 \\
\hline AN132 & 200 & 434 \\
\hline
\end{tabular}


Table 5: Maximum temperature tolerance of some selected HAPAM polymers. Polymers were evaluated under a shear rate of $170 / s$ and temperature range of $20-140^{\circ} \mathrm{C}$.

\begin{tabular}{|c|c|c|c|c|}
\hline Polymer* & Maximum Temperature $\left({ }^{\circ} \mathrm{C}\right)$ & $\mathrm{CAC}(\mathrm{g} / \mathrm{L})$ & Concentration Regime & Reference \\
\hline AM-AA-NDS-NIMA ${ }^{2}$ & 35 & 1.00 & Semi-dilute & (Gou et al. 2015) \\
\hline $\mathrm{AM}^{-\mathrm{AMC}_{12} \mathrm{~S}-\mathrm{DPP}}{ }^{3}$ & 35 & 0.20 & Semi-dilute & (Sun et al. 2015) \\
\hline AM-DOAC-SSS ${ }^{4}$ & 80 & & Semi-dilute (0.3 wt.\%) & (Quan et al. 2016) \\
\hline
\end{tabular}

*The abbreviations denoting the polymers are:

1. AM-AA-NIMA - HAPAM containing 3-(2-(2-Heptadec-8-enyl-4,5-dihydro-imidazol-1-yl)ethylcarbamoyl)acrylic acid (NIMA) and acrylic acid (AA)

2. AM-AA-NDS-NIMA - HAPAM containing 3-(2-(2-Heptadec-8-enyl-4,5-dihydro-imidazol-1-yl)ethylcarbamoyl)acrylic acid (NIMA), 3(diallyl-amino)-2- hydroxypropyl sulfonate (NDS) and acrylic acid (AA)

3. AM-AMC ${ }_{12} \mathrm{~S}-\mathrm{DPP}$ - HAPAM containing 1-(4-dodecyloxy-phenyl)-propenone (DPP) and 2-(acrylamido)-dodecanesulfonic acid $\left(\mathrm{AMC}_{12} \mathrm{~S}\right)$

4. AM-DOAC-SSS - HAPAM containing ionic hydrophobic monomer $N, N$-dimethyloctadeyl allyl ammonium chloride (DOAC) and the anionic monomer sodium 4-styrenesulfonate (SSS) 


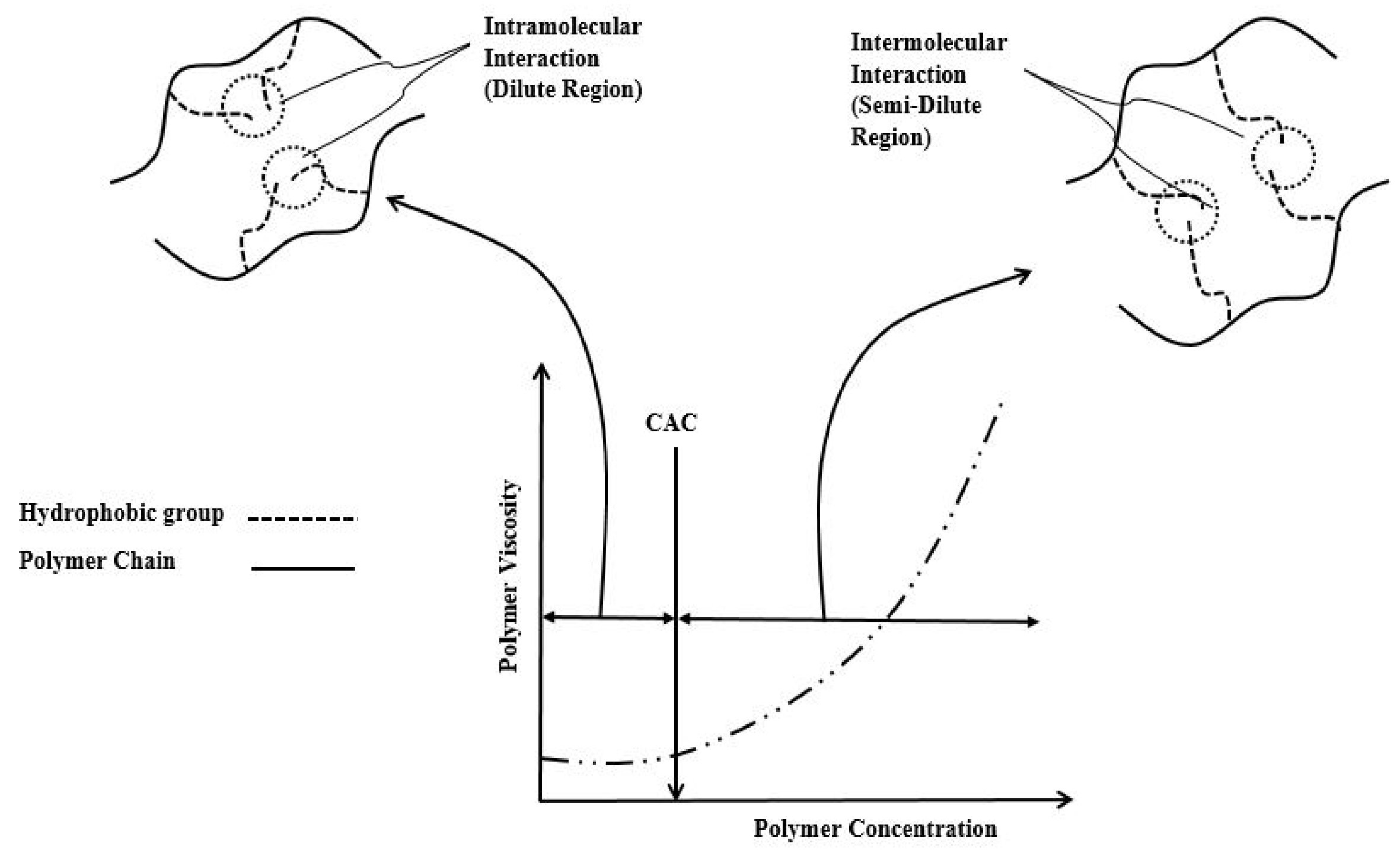

Figure 1: Viscosity behavior of hydrophobically associating polymers (HAPAM) before and after the critical aggregation concentration. 


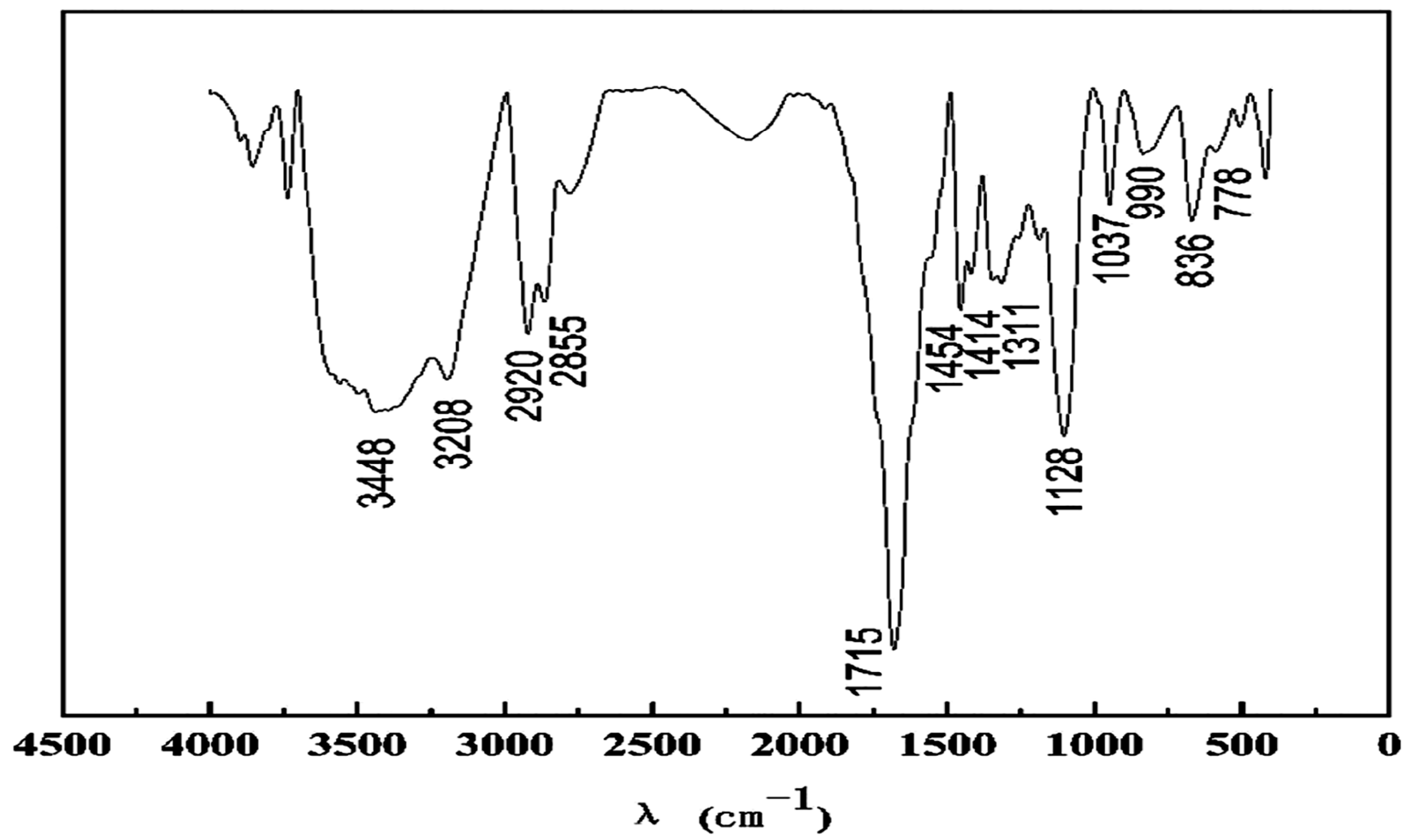

Figure 2: FTIR spectrum of a hydrophobically associating polymer (HPAAT) (Quan et al., 2019) 


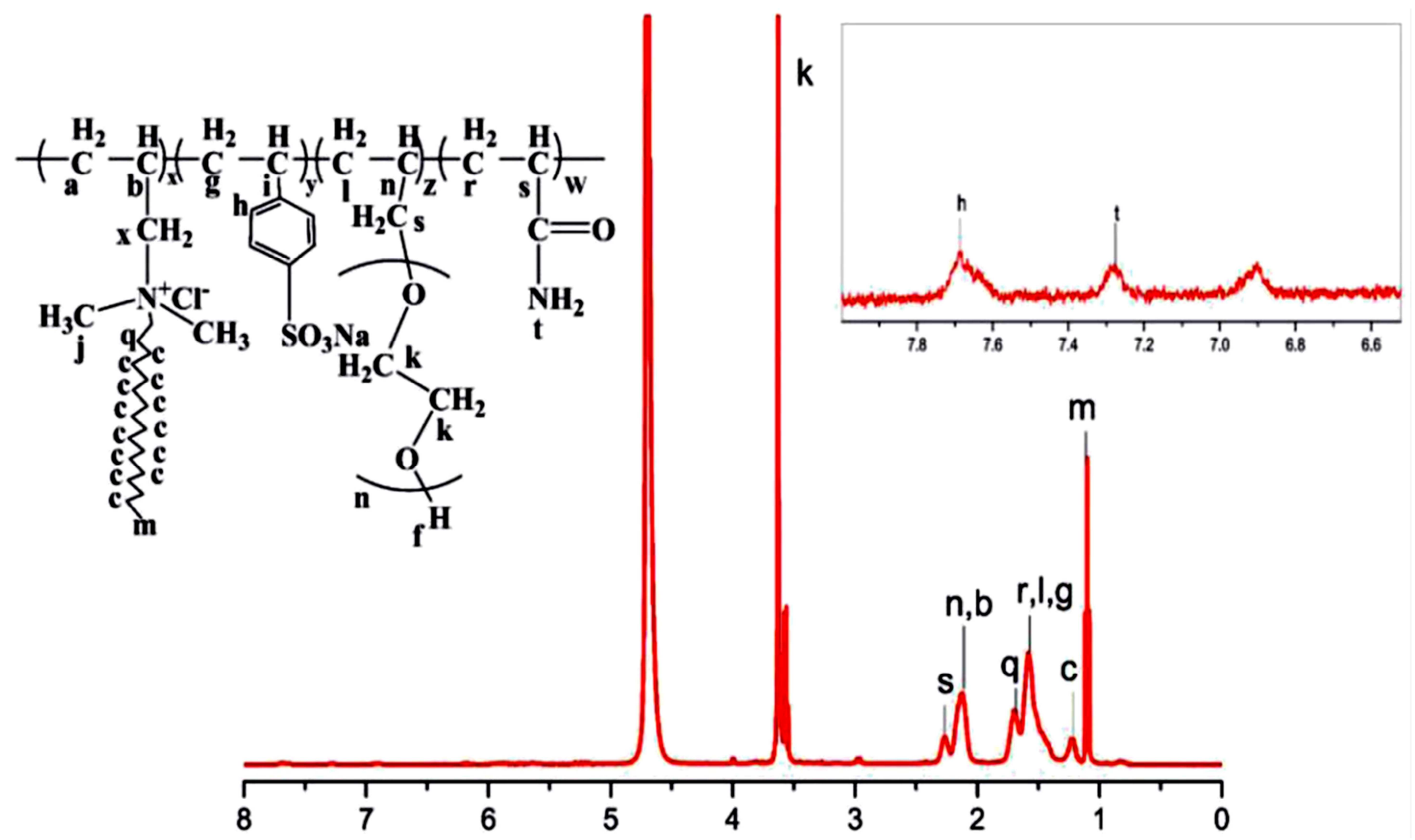

Figure 3: ${ }^{1}$ H-NMR spectrum of a hydrophobically associating polymer HPAAT by (Quan et al., 2019). 


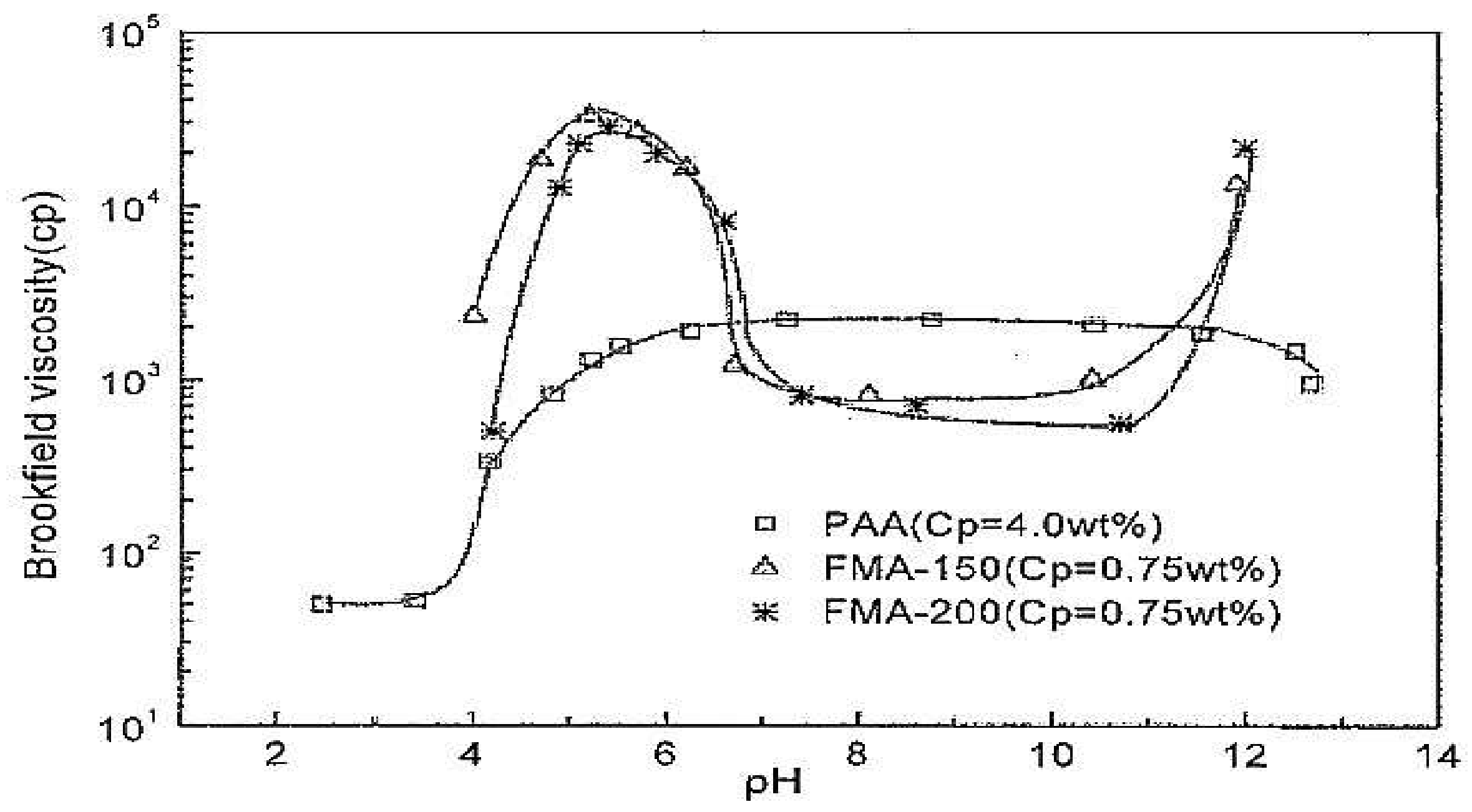

Figure 4: Effect of $\mathrm{pH}$ on the solution viscosity of poly (acrylic acid) (PAA) and their modified polymers (FMA) at temperature $25{ }^{\circ} \mathrm{C}$ and a shear rate of 0.4 /s (Zhou et al., 2001). 


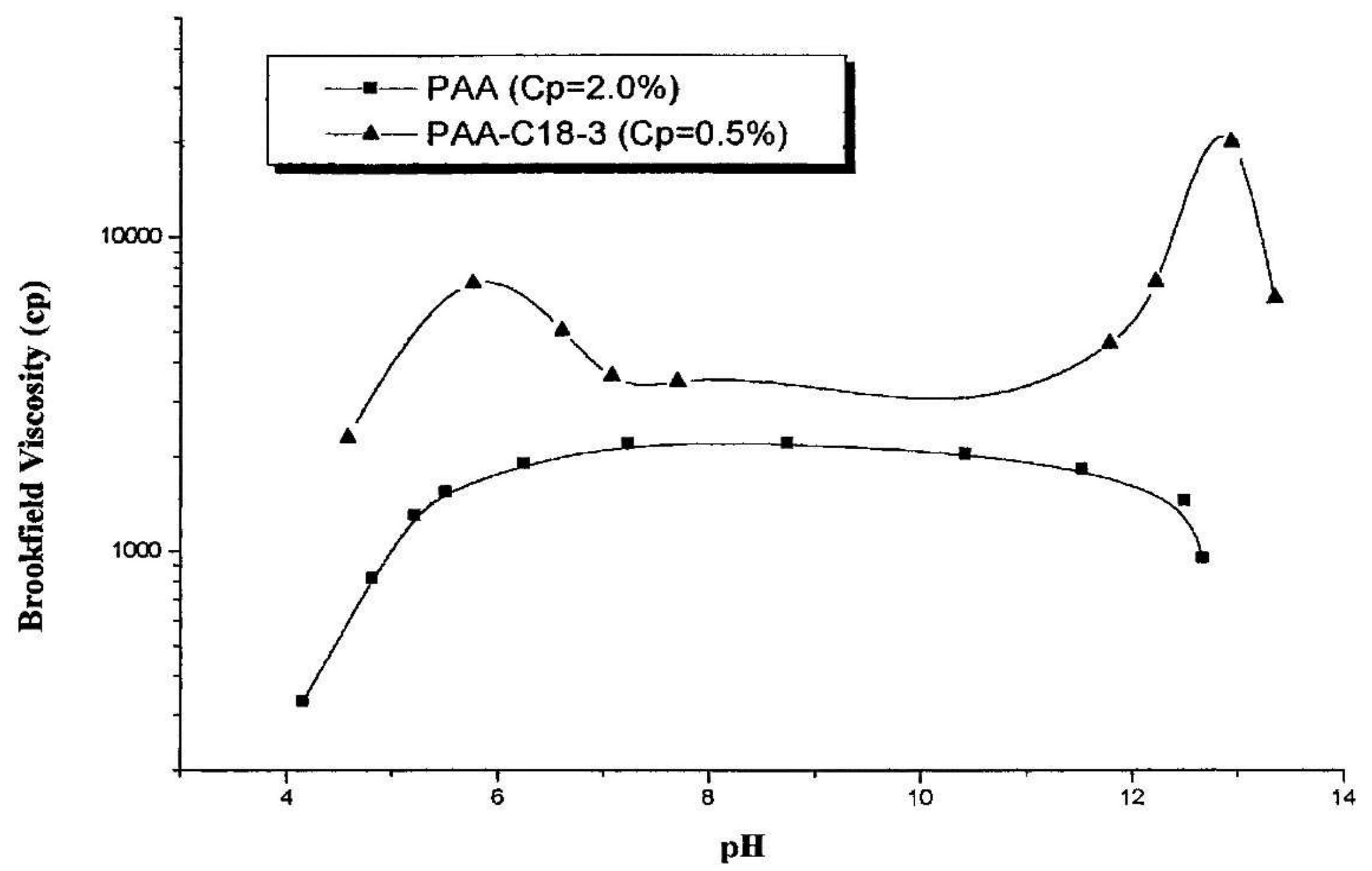


Figure 5: Effect of $p H$ on polymer viscosity of PAA and PAA modified with n-dodecyl acrylate/2-ethylhexyl acrylate (PAA-C) (Zhuang et al. 2001). 


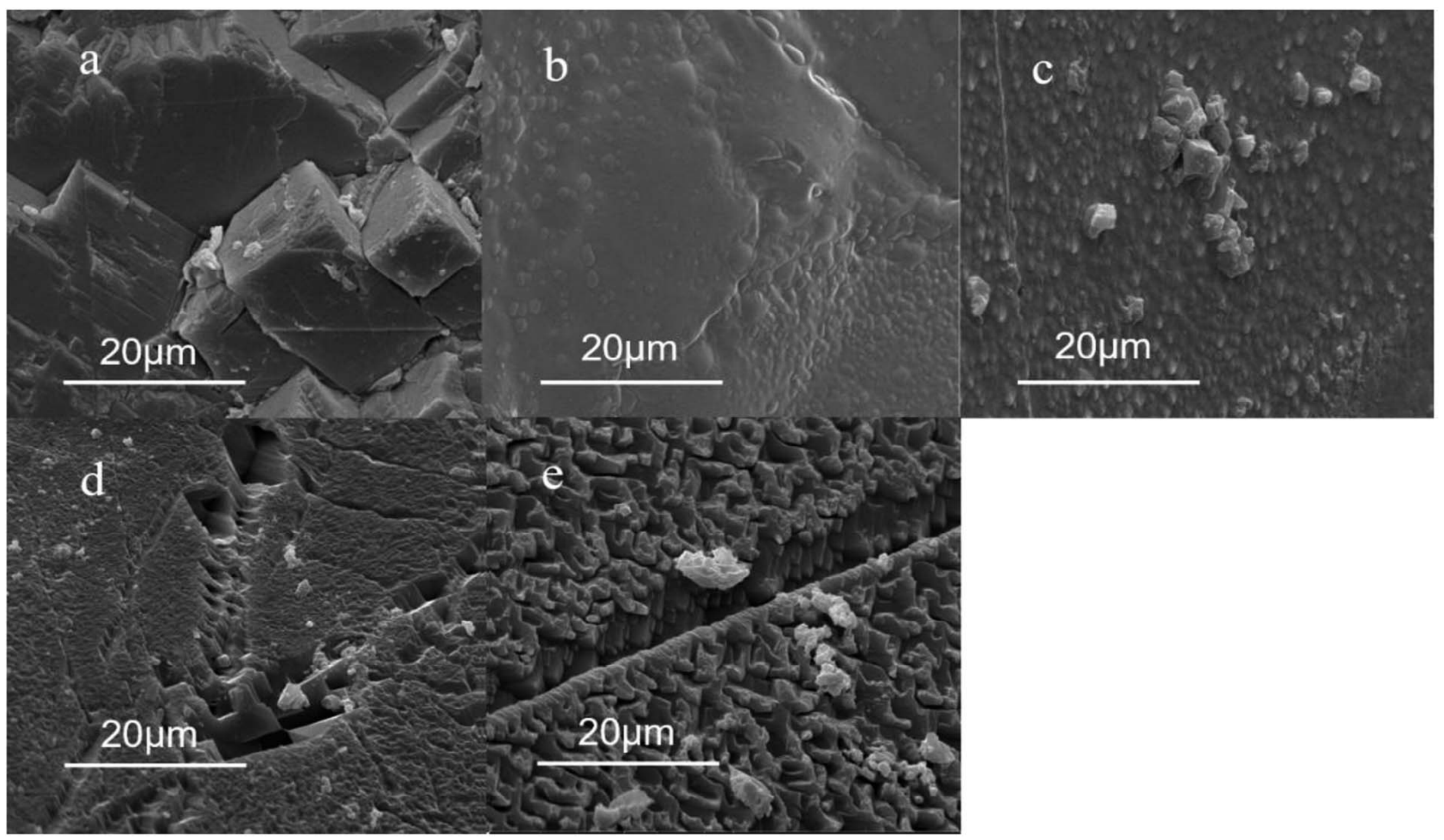

Figure 6: SEM images of the associative polymer (HPAAT) at various dissolution times: (a) the untreated carbonate sample, (b) $5000 \mathrm{mg} L^{-1}$ HPAAT-40 min (c) $8000 \mathrm{mg} \mathrm{L}^{-1}$ HPAAT-50 min, (d) $5000 \mathrm{mg} \mathrm{L}^{-1}$ HPAAT-55 min, and (e) $8000 \mathrm{mg} \mathrm{L}^{-1}$ HPAAT-65 min. (Quan et al., 2019). 


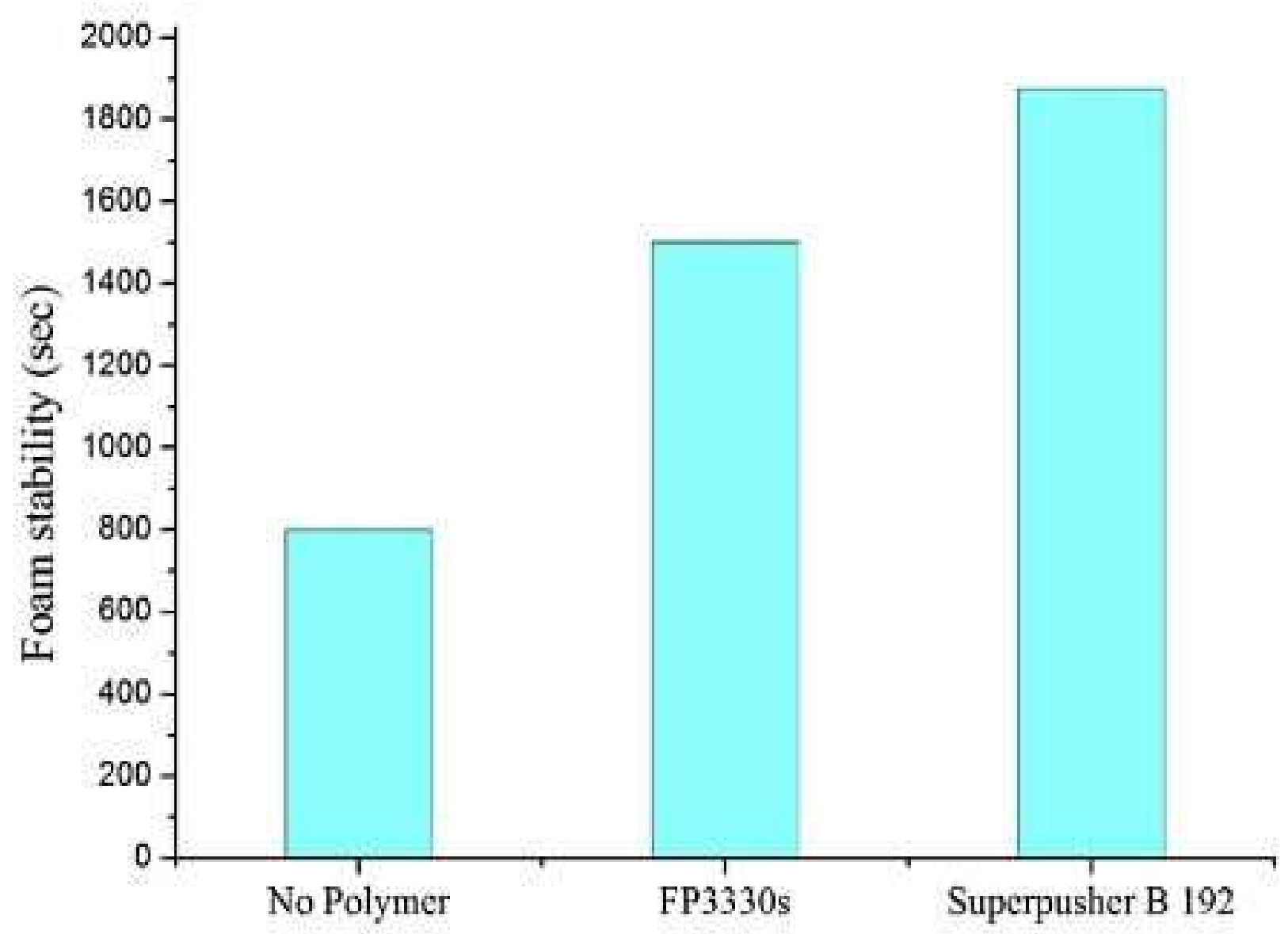

Figure 7: Foam stability comparison of PEFs containing no polymer, conventional polymer (FP3330s) and associative polymer (Superpusher B192) $\mathrm{CO}_{2}$ foams. The polymer concentration was $2000 \mathrm{ppm}$ at $3 \mathrm{wt} \% \mathrm{NaCl}, 80^{\circ} \mathrm{C}$ and $14.5 \mathrm{psi}$ (modified from Ahmed et al. (2017)). 


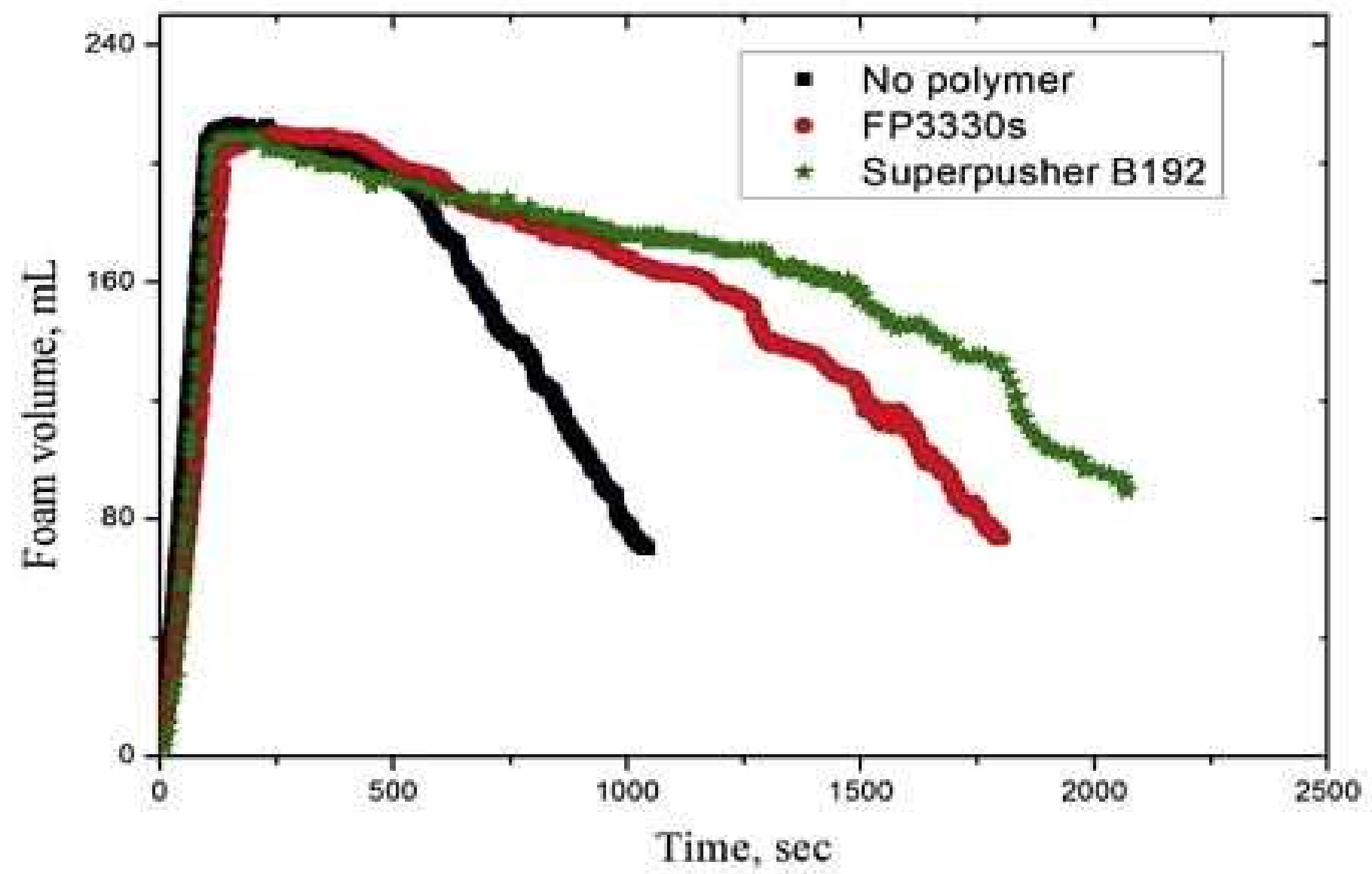

Figure 8: Foam volume comparison of PEFs containing no polymer, conventional polymer (FP3330s) and associative polymer (Superpusher B192) $\mathrm{CO}_{2}$ foams. The polymer concentration was $2000 \mathrm{ppm}$ at $3 \mathrm{wt} \% \mathrm{NaCl}, 80^{\circ} \mathrm{C}$ and $14.5 \mathrm{psi}$ (modified from Ahmed et al. (2017)). 